\title{
La protezione internazionale dei diritti umani dei giornalisti
}

\author{
Sejal Parmar ${ }^{1}$
}

\section{INTRODUZIONE}

Il presente capitolo riassume il quadro giuridico, inclusa la c.d. soft law, internazionale e regionale dei diritti umani in riferimento alla protezione dei giornalisti. ${ }^{2}$ Tramite l'analisi del diritto internazionale e regionale in materia di diritti umani, inclusa la giurisprudenza, si intende trarre un bilancio degli obblighi vigenti per gli Stati in tema di protezione dei giornalisti, una tematica che ha suscitato un interesse crescente negli ultimi anni. ${ }^{3}$ Il capitolo si concentrerà sulla protezione fisica dei giornalisti, tenendo presente che il termine "giornalista" viene interpretato in senso lato al fine di includere gli operatori mediatici, mentre con l'espressione "protezione" s'intende la prevenzione dagli attacchi fisici o aggressioni contro giornalisti, che possono (o meno) portare al decesso, ma non la tutela giuridica dei giornalisti in senso più ampio, affinché essi possano esercitare liberamente la loro professione. Per questo motivo, mentre il presente capitolo si rivolge a determinati argomenti che riguardano l'ambiente più ampio per la libertà di stampa, quali le leggi penali in materia di diffamazione e la protezione delle fonti giornalistiche, si astiene dall'analizzare in maniera più approfondita le sfide più importanti per la protezione dei giornalisti durante lo svolgimento della loro attività, p.es. le restrizioni all'accesso alle informazioni e alle scelte di sicurezza nazionale, incluse le misure di sorveglianza. Inoltre, il capitolo non si soffermerà sugli obblighi o sulle responsabi-

1 Assistant Professor di giurisprudenza, Central European University, Budapest.

2 Questo capitolo si basa su Sejel Parmar (2014), "The protection and safety of journalists: a review of international and regional human rights law", il paper redatto per il Seminario e Il Dialogo Interregionale sulla protezione dei giornalisti; e su "Towards an effective framework of protection for the work of journalists and an end to impunity", Corte europea dei diritti dell'uomo, Strasburgo, lunedì 3 novembre 2014. Vedi www.inter-justice.org per i paper le presentazioni utilizzate durante il seminario. L'autore è molto grato a Marina van Riel per i suoi preziosi commenti e la sua assistenza editoriale.

3 Per una selezione di articoli rilevanti pubblicati su riviste scientifiche, vedi Christof Heyns e sharath Srinivasan (2013). Vedi anche i seguenti paper: Carmen Draghici e Lorna Woods (2011); Evie Browne ed altri (2012). 
lità etiche in capo ai giornalisti. ${ }^{4}$ Per ragioni di spazio, non rientra inoltre tra gli scopi del presente capitolo chiarire il quadro giuridico internazionale in materia di leggi umanitarie, già affrontato in altra sede (Ben Saul 2008; Isabel Düsterhöft 2013). Basandosi su un'ampia gamma di fonti internazionali e regionali in materia di diritti umani, il capitolo punta ad identificare le componenti chiave che dovrebbero sostenere la creazione di una cornice legale e politica tollerante al fine di affrontare la sfida più urgente che i giornalisti e gli operatori mediatici si trovano ad affrontare, ovvero la violenza fisica o la minaccia della stessa. ${ }^{5} \mathrm{Il}$ presente capitolo sottolinea l'urgenza della tematica quale questione di rilevanza globale posta tra gli organi intergovernativi che si occupano di diritti umani e le organizzazioni non governative (ONG) negli anni recenti (punto 2) ed alcune tematiche preliminari chiave nel riconoscere che la protezione dei giornalisti è una questione inerente ai diritti umani (punto 3). L'analisi si concentrerà poi sull'applicazione degli obblighi degli Stati che variano dalla cornice giuridica internazionale e locale alla protezione dei giornalisti e degli operatori mediatici.

\section{UNA QUESTIONE DI RILEVANZA GLOBALE}

Sembra che l'anno 2014 sia stato particolarmente funesto per i giornalisti e degli operatori mediatici, mentre i tre anni che precedettero il dicembre del 2014 vennero definiti dal Comitato per la protezione dei giornalisti il "periodo più letale" dall'inizio delle rilevazioni nel 1992.6 Il 2014 è stato

4 Queste problematiche sono state analizzate approfonditamente dalla prospettiva della giurisprudenza della Corte europea dei Diritti dell'Uomo da Philip Leach (2013). Vedi anche Tarlach McGonagle (2013).

5 Come è stato sottolineato dal Relatore speciale OSA, "per l'esistenza di un dibattito libero, solido e illimitatamente democratico, la violenza contro i giornalisti deve essere combattuta attraverso politiche globali di prevenzione, protezione e acquisizione di giustizia” (Commissione interamericana dei diritti umani 2013:22).

6 Il 2 aprile 2015 l'organizzazione contò 1121 giornalisti uccisi a partire dal 1992; segnalando i seguenti 10 come i paesi più pericolosi: Iraq (166), Siria (80), Filippine (77), Algeria (60), Somalia (56), Russia (56), Pakistan (56), Colombia (46), India (34) and Mexico (32). L'organizzazione riportò che il Medio Oriente e il Nord Africa erano risultate come le regioni più pericolose per i giornalisti e, mentre aumentava drasticamente il numero di giornalisti internazionali uccisi sul lavoro nel 2014, molti di questi erano giornalisti locali (Committee to Protect Journalists 2014b). Vedi le statistiche fornite da Committee to Protect Journalist www.cpj.org/ killed/ and www.cpj.org/killed/impunity.php, consultato il 13 luglio 2015. 
segnato, in particolare, dalle orribili decapitazioni in video dei due giornalisti freelance americani rapiti in Siria nel 2012 e nel 2013, James Foley e Steven Sotloff, per mano di un militante del c.d. "Stato Islamico" (o ISIS), senza considerare l'assassinio dei restanti almeno 15 giornalisti durante la guerra in Siria nel 2014, l'assassinio di almeno 17 giornalisti ed operatori mediatici nel conflitto nella Striscia di Gaza, l'arresto, la detenzione e l'aggressione nei confronti dei giornalisti durante le proteste a Ferguson, in Missuri, negli Stati Uniti e le percosse che hanno fatto svenire Ilgar Nasibov nell'ambito del giro di vite contro i media in Azerbaijan mentre il Paese presiedeva il Comitato dei Ministri del Consiglio d'Europa. ${ }^{7}$ Inoltre, va menzionato l'assassinio di otto giornalisti e vignettisti negli uffici della rivista Charlie Hebdo a Parigi il 7 gennaio 2015, il che evidenziò più di qualsiasi altro evento il fatto che gli attacchi al giornalismo sono di rilevanza mondiale. Si tratta infatti di una problematica che affligge non solo i Paesi in conflitto o governati da regimi repressivi, ma anche gli Stati considerati liberi, le roccaforti tradizionali della libertà di parola (Parmar 2015). La protezione dei giornalisti è diventata, di conseguenza, una tematica di importanza mondiale, in quanto riguarda gli Stati di tutti i continenti, sia le democrazie che i regimi più autoritari.

Anche prima dei drammatici eventi a danno dei giornalisti avvenuti nel 2014 e all'inizio del 2015 vi fu, per qualche anno, una crescente consapevolezza mondiale circa le sfide messe in capo da tali attacchi, grazie a mezzi di difesa più efficaci e ricerche in tema. Come ribadisce il rapporto UNESCO del 2014 "World trends in freedom of expression and media develpoment", gli "ultimi sei anni hanno visto sia un aumento degli assassini contro i giornalisti sia un aumento della consapevolezza internazionale sul tema" (UNESCO 2014: 11, 84-95). Come parte delle loro strategie di difesa, le ONG che si impegnano a proteggere i giornalisti in quanto tali (per esempio, il Comitato per la protezione dei giornalisti), la libertà di espressione in senso più ampio (per esempio, Article 19) ed i diritti umani in generale (per esempio, Human Rights Watch) hanno stilato relazioni, monitorando ed analizzando gli sviluppi ed elaborando raccomandazioni per una vasta gamma di soggetti, tra i quali i governi, nonché i giornalisti stessi. Il rapporto del Comitato per la protezione dei giornalisti "The road to justice; breaking the cycle of impunity", pubblicato in occasione della prima Giorna-

7 Vedi Ravi Somaiya and Christine Haughney (2014). Per i rapporti pubblicati in merito a questi vari incidenti vedi: Rukmini Callimachi (2014); Max Fisher (2014); Raziye Akkoc (2014); IMEMC News \& Agencies (2014); Radio Free Europe/Radio Liberty Azerbaijani Service (2014). 
ta mondiale per mettere fine all'impunità per i crimini contro i giornalisti celebrata il 2 novembre 2014, è uno di tali rapporti (Comitato per la protezione dei giornalisti 2014a). Nel corso degli anni, alcune organizzazioni hanno anche sviluppato degli strumenti per consentire ai giornalisti e agli operatori mediatici di difendersi autonomamente dagli attacchi, per esempio dei manuali di autoprotezione. ${ }^{8}$ Il 12 febbraio 2015, in risposta agli attacchi ai giornalisti, una coalizione globale di organizzazioni ha adottato $\mathrm{i}$ "Global safety principles and practices" per le organizzazioni mediatiche internazionali ed i giornalisti freelance (Dart Centre for Journalism and Trauma 2015). Il Comitato internazionale della Croce Rossa (CICR) ha anche mantenuto un numero verde, esistente da tempo, per i giornalisti che svolgono incarichi pericolosi. ${ }^{9}$

Alla emergente consapevolezza globale corrisponde l'impegno crescente di organi internazionali nel campo dei diritti umani per la protezione e la sicurezza dei giornalisti, i quali intervengono presso gli Stati per rispondere alla sfida degli attacchi ai giornalisti. Segnalando un senso di grande urgenza, il 1 settembre 2014 i quattro esperti intergovernativi che si occupano della libertà di espressione (ovvero, il Relatore speciale delle Nazioni Unite sulla promozione e la protezione della libertà di opinione e di espressione, David Kaye; il Rappresentante dell'Organizzazione per la sicurezza e la cooperazione in Europa (OSCE) per la libertà dei media, Dunja Mijatović, il Relatore speciale dell'Organizzazione degli Stati Americani (OSA) per la libertà di espressione, Catalina Botero Marino, e il Relatore speciale della Commissione Africana dei diritti dell'uomo e dei popoli sulla libertà di espressione e sull'accesso all'informazione, Faith Pansy Tlakula) hanno elaborato una presa di posizione comune nella quale si richiede una protezione più forte per i giornalisti che operano nelle zone di conflitto, con riferimento ai contesti specifici di Siria, Ucraina, Iraq e Gaza (Alto commissariato delle Nazioni Unite per i diritti umani 2014).

Una serie di istituzioni intergovernative hanno già affrontato il tema della protezione dei giornalisti per diversi anni a seguito dell'adozione della storica Risoluzione del Consiglio di sicurezza delle Nazioni Unite1738 nel 2006 relativa agli attacchi perpetrati contro i giornalisti nelle zone di conflitto (Consiglio di sicurezza delle Nazioni Unite2016). L'attenzione ri-

8 Vedi i seguenti esempi di manuali di autodifesa: Article 19 (2013); Comitato per la protezione dei giornalisti (2012); Reporter senza frontiere (2006); Reporter senza frontiere (2002).

9 Il Comitato internazionale per la Croce Rossa stabilì nel 1985, a seguito di una richiesta avanzata dai 16 maggiori emittenti, una linea rossa. Vedi Comitato internazionale per la Croce Rossa (2012). 
volta alle istituzioni che si occupano di diritti umani, incrementata presso l'ONU a partire dal 2012, comprende: l'adozione delle Risoluzioni del Consiglio sui Diritti Umani 21/12 del 27 settembre 2012 (Consiglio dei diritti umani delle Nazioni Unite 2012a) e 27/5 del 25 settembre 2014 (Consiglio per i diritti umani delle Nazioni Unite 2014a) sulla sicurezza dei giornalisti, e la Decisione del Consiglio per i diritti umani delle Nazioni Unite 24/116 del 26 settembre 2013 su una discussione in materia (Consiglio per i diritti umani delle Nazioni Unite 2013a);10 l'adozione della Risoluzione dell'Assemblea Generale 68/163 del 18 dicembre 2013 sulla sicurezza dei giornalisti e sul tema dell'impunità che ha dichiarato il 2 novembre la Giornata internazionale per il fine dell'impunità per i crimini commessi contro i giornalisti (Assemblea Generale delle Nazioni Unite 2013); lo sviluppo e la presentazione dei rapprti di due incaricati dell'ONU sul diritto alla libertà di opinione e di espressione (Consiglio per i diritti umani delle Nazioni Unite 2012b) e sulle esecuzioni extragiudiziali, sommarie o arbitrarie con al centro dell'attenzione la protezione dei giornalisti (Consiglio per i diritti umani delle Nazioni Unite 2012c) e la ventunesima sessione del Consiglio sui Diritti Umani nel giugno del 2012; il rapporto del Segretario generale sulla protezione dei civili nei conflitti a fuoco del maggio del 2012 che evidenzia gli attacchi ai giornalisti (Consiglio di sicurezza delle Nazioni Unite 2012: paragrafi 5, 14 e 15); una serie di discussioni informali del Consiglio di sicurezza delle Nazioni Unitesulla protezione dei giornalisti nel corso del 2013 (UN News Centre 2013a, 2013b); il sostegno del Piano di azione delle Nazioni Unite sulla sicurezza dei giornalisti e sul problema dell'impunità da parte del Consiglio dei direttori esecutivi degli organismi delle Nazioni Unite per il coordinamento del 12 aprile 2012 e lo sviluppo di indicatori di sicurezza per valutare i passi intrapresi verso l'implementazione del piano di azione ONU sulla sicurezza dei giornalisti e sul problema dell'impunità (il "Piano di azione ONU") (UNESCO 2012, 2013a, 2013b, 2013c); e rilevanti dichiarazioni e decisioni dell'UNESCO nel 2012 e nel 2013. ${ }^{11}$ Nel giugno del 2012 i quattro meccanismi internazionali per la promozione della libertà di espressione hanno adottato una

10 Vedi anche il riassunto della discussione sulla sicurezza dei giornalisti del Consiglio per i diritti umani delle Nazioni Unite (Consiglio per i diritti umani delle Nazioni Unite 2014b); Risoluzione del Consiglio per i diritti umani delle Nazioni Unite 27/5, 2 ottobre 2014 A/HRC/RES/27/5.

11 Vedi le dichiarazioni in occasione della Giornata mondiale della libertà di stampa, con particolare attenzione alla Dicharazione di Cartagine 3 maggio 2012 (a supporto del piano di azione ONU sulla sicurezza dei giornalisti e la questione dell'impunità) e la Dichiarazione di San Jose, 4 maggio 2013. Vedi anche UNE- 
Dichiarazione comune sui crimini contro la libertà di espressione (la "Dichiarazione comune del 2012"), la quale definisce espressamente i giornalisti e gli altri attori mediatici le vittime più esposte a tali crimini. ${ }^{12}$ Questa dichiarazione abbastanza recente dei quattro esperti intergovernativi sulla libertà di espressione viene ritenuta un punto di riferimento chiave per identificare gli standard più specifici applicabili agli Stati nel rispetto della protezione della sicurezza dei giornalisti, nonostante non abbia carattere vincolante.

Nelle Americhe, il Relatore speciale delle Nazioni Unite sulla libertà di opinione e di espressione e il Relatore speciale per la libertà di espressione della Commissione interamericana OSA sui diritti umani (IACHR) hanno pubblicato una presa di posizione comune sulla "violenza contro i giornalisti e gli operatori mediatici nel contesto delle proteste" nel settembre del 2013 (ONU e OSA 2013). L'Ufficio del Relatore speciale sulla libertà di espressione della Commissione ha inoltre pubblicato una relazione analitica significativa, "Violence against journalists and media workers: Inter-American standards and national practices on prevention, protection and prosecution of perpetrators" alla fine del 2013 (Commissione interamericana dei diritti umani 2013, 2014), sebbene l'ufficio condanni regolarmente gli attacchi contro i giornalisti nella regione. ${ }^{13} \mathrm{Nel}$ marzo del 2014, la Commissione interamericana dei diritti umani ha tenuto un'udienza sull'”Impunità per le violazioni dei diritti alla libertà di espressione nelle Americhe" (Commissione interamericana dei diritti umani 2014b).

SCO General Conference Resolution 29 sullla condanna della violenza contro i giornalisti, 12 novembre 1997; Dichiarazione di Belgrado a supporto degli emittenti media in paesi caratterizzati da conflitti violenti e da periodi di transizione governativa, 3 maggio 2004; Dichiarazione di Medellin sulla sicurezza dei giornalisti e l'opposizione all'impunità, 4 maggio 2007; e le decisioni del programma internazionale per lo sviluppo delle comunicazione (IPDC) relative alla sicurezza dei giornalisti e l'impunità del 27 marzo 2008, 10 marzo 2010 e 23 marzo 2012.

12 La Dichiarazione congiunta indica che i crimini contro la libertà d'espressione includono: "omicidi, minacce di morte, sparizioni, sequestri di persona, prese in ostaggio, arresti arbitrari, persecuzioni e imprigionamenti, torture e trattamenti inumani o degradanti, molestie, intimidazioni, deportazione e confisca di o danneggio ad equipaggiamenti e proprietà." Vedi Ufficio dell'Alto commissario delle Nazioni Unite per i diritti umani (2012).

13 Per esempi relativi a dichiarazioni dell'Ufficio del Relatore speciale sulla libertà d'espressione in agosto 2014, vedi OSA IACHR, Ufficio del Relatore speciale sulla libertà d'espressione, documento 89/14, 21 agosto 2014 (sulla morte di un giornalista in Honduras); 87/14, 16 agosto 2014 (sulla morte di un giornalista in Messico); 85/14, 4 agosto 2014 (sull'uccisione di un giornalista in Colombia); 83/14, 6 agosto 2014 (sull'attacco a un giornalista e l'uccisione di suo figlio in Messico). 
A livello regionale europeo le istituzioni del Consiglio d'Europa hanno manifestato particolare interesse per la protezione dei diritti umani nel corso degli anni tramite una serie di iniziative rilevanti, dichiarazioni, risoluzioni, raccomandazioni ed altre iniziative. ${ }^{14}$ Nell'aprile del 2015, il Consiglio d'Europa ha lanciato in stretta cooperazione con cinque organizzazioni partner la "Piattaforma per proteggere il giornalismo e promuovere la sicurezza dei giornalisti", la quale mira a fornire informazioni alle istituzioni del Consiglio d'Europa sulle minacce fisiche rivolte contro i giornalisti e gli operatori mediatici. ${ }^{15}$ Nell'aprile del 2014, il Comitato dei Ministri del Consiglio d'Europa ha adottato una dichiarazione sulla "protezione del giornalismo e la sicurezza dei giornalisti ed altri operatori mediatici" (Comitato dei Ministri del Consiglio d'Europa 2013b) verso la fine della presidenza austriaca del Comitato, la quale considerava la sicurezza dei giornalisti una priorità strategica, ${ }^{16}$ e, nel novembre del 2013, la Conferenza dei Ministri del Consiglio d'Europa responsabili dei i media e della società dell'informazione (2013) ha adottato una risoluzione sulla sicurezza dei giornalisti nell'ambito di una conferenza tenutasi a Belgrado. Vi sono stati inoltre dibattiti tematici del Comitato dei Ministri sulla sicurezza dei giornalisti fin dal 2012 (Comitato dei Ministri del Consiglio d'Europa 2012, 2013a, 2014a), la prima riunione del neocostituito Comitato di esperti sulla protezione del giornalismo e la sicurezza dei giornalisti nel marzo del 2014, così come la tavola rotonda per la promozione del dialogo tra le istituzioni internazionali tenutasi a Strasburgo nel maggio del $2014 .{ }^{17} \mathrm{Fin}$ dal 2011, l'Assemblea parlamentare ha adottato una risoluzione sulla "condizione della libertà mediatica in Europa" (Assemblea parlamentare del Consiglio d'Europa 2013) evidenziando gli obblighi degli Stati "per proteggere

14 Per un elenco di iniziative iniziate da organi del Consiglio d'Europa, vedi www.coe.int/t/dghl/standardsetting/media/roundtable-en.asp, consutato il 14 luglio 2015.

15 Vedi www.coe.int/en/web/media-freedom, consultato il 14 luglio 2015. Le 5 organizzazione partner sono: Article 19, Associazione europea dei giornalisti, Federazione europea dei giornalisti, Federazione internazionale dei giornalisti e reporter senza frontiere.

16 La presidenza austriaca affermò: "La libertà d'espressione e la sicurezza dei giornalisti saranno i principali punti d'azione degli sforzi austriaci”. Consultare Priorità della Presidenza austriaca del Comitato dei Ministri del Consiglio d'Europa (14 novembre 2013-14 maggio 2014), 5 novembre 2013 CM/Inf (2013) 32.

17 Comitati di esperti del Consiglio d'Europa sulla protezione e sicurezza dei giornalisti (MSJ-JO), primo incontro 3-4 marzo 2014, 10 marzo 2014, MSJ-JO (2014)3; Tavola rotonda sulla sicurezza dei giornalisti: impegno all'azione, 19 maggio 2014 Strasburgo. 
i giornalisti contro gli attacchi alle loro vite e la libertà di espressione, e prevenire l'impunità degli autori", così come una raccomandazione sulla protezione delle fonti giornalistiche (Assemblea parlamentare del Consiglio d'Europa 2011). La "protezione dei giornalisti dalla violenza" è stato il soggetto di un paper di discussione in materia prodotto dal Commissario per i diritti umani nel 2011 (Commissario per i diritti umani del Consiglio d'Europa 2011), così come alcune pubbliche dichiarazioni. ${ }^{18}$ È interessante notare che "combattere la violenza, la persecuzione, le molestie e le intimidazioni degli individui, inclusi i giornalisti ed altri attori mediatici ... e ... l'impunità di tali crimini" sono state ritenute aree di azione prioritarie del Consiglio d'Europa nelle "Linee guida UE sulla libertà di espressione online e offline" (Consiglio dell'Unione Europea 2014).

Nella più vasta regione dell'OSCE, il Rappresentante per la libertà dei media ha adottato insieme al presidente lituano dell'organizzazione nel giugno del 2011 la "Raccomandazione di Vilnius sulla sicurezza dei giornalisti” (OSCE 2011), una serie di linee guida per i governi nazionali, i legislatori, le agenzie di law-enforcement e i media finalizzate a garantire ai giornalisti condizioni di lavoro sicure. Nel 2013 l'Ufficio del Rappresentante per la libertà dei media ha lanciato la campagna "End impunity" per mettere in luce le minacce contro i giornalisti nella regione (OSCE 2013) e, nel 2014, ha pubblicato la seconda edizione del "Safety for journalists guidebook" (OSCE 2014a). L'Ufficio del Rappresentante per la libertà dei media sembra essere un meccanismo internazionale particolarmente prolifico per la promozione della libertà di espressione, in quanto ritiene $i$ casi di attacchi individuali contro i giornalisti e gli operatori mediatici le minacce maggiori alla libertà dei media nella regione (OSCE 2014b). ${ }^{19}$ Il Rappresentante Dunja Mijatović ha recentemente condannato gli attacchi ai giornalisti in Paesi quali la Russia, l'Ucraina e gli Stati Uniti. ${ }^{20}$ È una precursore nel campo dei meccanismi intergovernativi sul particolare, ma crescente problema delle minacce online alle giornaliste donne (OSCE 2015).

18 Vedi anche Commissario per i diritti umani del Consiglio d'Europa (2012, 2014). www.coe.int/t/dghl/standardsetting/media/ Round\%20table\%20outline_en.pdf, ultimo accesso: 14 luglio 2015.

19 Vedi anche Dunja Mijatović (2011).

20 Vedi, per esempio, OSCE (2014c, 2014d, 2014e, 2014f). 


\section{I DIRITTI UMANI E LA PROTEZIONE DEI GIORNALISTI: QUESTIONI PRELIMINARI}

\subsection{Tutela dei diritti}

I giornalisti e gli operatori mediatici possono subire attacchi di vario genere che spaziano dalla violenza fisica e dalle aggressioni, dai sequestri di persona e dalle scomparse, alle minacce, intimidazioni e molestie. Le giornaliste donna sono particolarmente esposte agli abusi sessuali, alle aggressioni e alle violenze, così come agli attacchi online ${ }^{21}$ I giornalisti in generale possono sentirsi minacciati o costretti da misure adottate contro di loro in quanto giornalisti da parte di autorità statali, per esempio la restrizione della libertà di movimento, il sequestro e la confisca dei beni di loro proprietà (p.es. appunti, memorie esterne, foto- e videocamere, hard drives) e sanzioni a seguito del rifiuto di rilevare le proprie fonti, o tramite un clima ostile ai media in generale, tramite forme di censura esplicita (p.es. vietando o bloccando un sito internet), la penalizzazione della diffamazione, regimi autorizzativi, o l'autorizzazione, le leggi nazionali in materia di sicurezza e programmi di sorveglianza. ${ }^{22}$ Questa serie di attacchi contro i giornalisti durante l'esecuzione delle loro mansioni lavorative comporta conseguenze di vario genere: i morti vengono silenziati per l'eternità; chi sopravvive agli attacchi e chi subisce minacce tende a non proseguire il proprio lavoro, optando, nella maggior parte dei casi, per l'autocensura; altri operatori mediatici, spaventati da ciò che vedono, scelgono la stessa strada; al pubblico è preclusa la possibilità di cercare e di ottenere informazioni libere quale risultato dell"'effetto dissuasivo" che nasce, in particolare, nei giornalisti stessi; l'impunità che quasi sempre segue un omicidio o un attacco rende eventuali futuri omicidi o attacchi semplicemente più probabili, e le opportunità di un dibattito democratico nonché il controllo e la responsabilità delle istituzioni dello Stato e dei soggetti privati che detengono il potere diminuiscono.

21 Per uno studio interessante sugli attacchi alle donne giornaliste e ai giornalisti in prima linea vedi Alana Barton e Hannah Storm (2014). Vedi anche Comitato per i diritti umani delle Nazioni Unite (2012b: paragrafi: 52, 94); Comitato per i diritti umani delle Nazioni Unite (2012c: paragrafo 107); e Jennifer R Henrichsen, Michelle Betz e Joanne M. Lisosky (2015: 43-62).

22 Vedi Ufficio dell'Alto commissario delle Nazioni Unite per i Diritti Umani (2012). 
Casi di attacchi e minacce contro i giornalisti sono collegati ad una serie di strumenti previsti dal diritto internazionale e regionale in materia di diritti umani, in particolare:

A. il diritto alla vita $e x$ art. 3 della Dichiarazione universale dei diritti umani, art. 6 del Patto internazionale sui diritti civili e politici, art. 2 della Convenzione europea dei diritti dell'uomo, art. 4 della Convenzione americana sui diritti umani e art. 4 della Carta africana dei diritti dell'uomo e dei popoli;

B. il diritto alla libertà di opinione e di espressione ex art. 19 della Dichiarazione universale dei diritti umani, art. 19 del Patto internazionale sui diritti civili e politici, art. 10 della Convenzione europea dei diritti dell'uomo, art. 14 della Convenzione americana sui diritti umani e art. 9 della Carta africana dei diritti dell'uomo e dei popoli.

Mentre il diritto alla vita e alla libertà di espressione furono i diritti chiave nella giurisprudenza rilevante e nelle considerazioni autoritative sugli attacchi ai giornalisti, possono essere coinvolti anche altri diritti umani, in particolare (Leach 2013):

A. il divieto di tortura e di trattamenti o punizioni crudeli, disumani o degradanti ex art. 5 della Dichiarazione universale dei diritti umani, art. 7 del Patto internazionale sui diritti civili e politici, art. 3 della Convenzione europea dei diritti dell'uomo, art. 5 della Convenzione americana sui diritti umani e art. 5 della Carta africana dei diritti dell'uomo e dei popoli;

B. il diritto alla libertà e alla sicurezza ex art. 3 della Dichiarazione universale dei diritti umani, art. 9 del Patto internazionale sui diritti civili e politici, art. 5 della Convenzione europea dei diritti dell'uomo, art. 7 della Convenzione americana sui diritti umani e art. 6 della Carta africana dei diritti dell'uomo e dei popoli;

C. il diritto al giusto processo $e x$ art. 10 della Dichiarazione universale dei diritti umani, art. 14 del Patto internazionale sui diritti civili e politici, art. 6 della Convenzione europea dei diritti dell'uomo, art. 8 della Convenzione americana sui diritti umani e art. 7 della Carta africana dei diritti dell'uomo e dei popoli;

D. il diritto alla libertà di pensiero, coscienza e religione ex art. 18 della Dichiarazione universale dei diritti umani, art. 18 del Patto internazionale sui diritti civili e politici, art. 9 della Convenzione europea dei diritti dell'uomo, art. 12 della Convenzione americana sui diritti umani e art. 8 della Carta africana dei diritti dell'uomo e dei popoli; 
E. il diritto alla privacy, alla famiglia, alla casa o corrispondenza ex art. 12 della Dichiarazione universale dei diritti umani, art. 17 del Patto internazionale sui diritti civili e politici, art. 8 della Convenzione europea dei diritti dell'uomo e art. 11 della Convenzione americana sui diritti umani;

F. il diritto alla libertà di riunione e associazione $e x$ art. 20 della Dichiarazione universale dei diritti umani, artt. 21 e 22 del Patto internazionale sui diritti civili e politici, art. 11 della Convenzione europea dei diritti dell'uomo, artt. 15 e 16 della Convenzione americana sui diritti umani e artt. 10 e 11 della Carta africana dei diritti dell'uomo e dei popoli;

G. il diritto ad un rimedio effettivo o alla tutela giudiziaria $e x$ art. 8 della Dichiarazione universale dei diritti umani, art. 2 del Patto internazionale sui diritti civili e politici, art. 13 della Convenzione europea dei diritti dell'uomo e art. 25 della Convenzione americana sui diritti umani;

H. il diritto alla proprietà $e x$ art. 17 della Dichiarazione universale dei diritti umani, art. 1 del Protocollo num. 1 della della Convenzione europea dei diritti dell'uomo, art. 21 della Convenzione americana sui diritti umani e art. 14 della Carta africana dei diritti dell'uomo e dei popoli;

I seguenti capitoli si concentrano sull'interpretazione delle previsioni chiave internazionali e regionali in materia di diritto alla vita e alla libertà di espressione. Le previsioni chiave sul diritto alla vita sono le seguenti:23

\section{Art. 3 della Dichiarazione universale dei diritti umani}

Ogni individuo ha diritto alla vita, alla libertà ed alla sicurezza della propria persona.

\section{Art. 6 del Patto internazionale sui diritti civili e politici}

Il diritto alla vita è inerente alla persona umana. Questo diritto deve essere protetto dalla legge. Nessuno può essere arbitrariamente privato della vita.

\section{Art. 2 della Convenzione europea dei diritti dell'uomo}

1. Il diritto alla vita di ogni persona è protetto dalla legge. Nessuno può essere intenzionalmente privato della vita, salvo che in esecuzione di una sentenza capitale pronunciata da un tribunale, nel caso in cui il reato sia punito dalla legge con tale pena.

23 Le disposizioni sulla pena di morte sono state escluse. 
2. La morte non si considera cagionata in violazione del presente articolo se è il risultato di un ricorso alla forza resosi assolutamente necessario:

(a) per garantire la difesa di ogni persona contro la violenza illegale;

(b) per eseguire un arresto regolare o per impedire l'evasione di una persona regolarmente detenuta;

(c) per reprimere, in modo conforme alla legge, una sommossa o un'insurrezione.

\section{Art. 4 della Convenzione americana sui diritti umani}

1. Ogni persona ha diritto al rispetto della propria vita. Tale diritto è protetto dalla legge e, in generale, dal momento del concepimento. Nessuno sarà arbitrariamente privato della vita.

\section{Art. 4 della Carta africana dei diritti dell'uomo e dei popoli}

La persona umana è inviolabile. Ogni essere umano ha diritto al rispetto della sua vita e all'integrità fisica e morale della sua persona. Nessuno può essere arbitrariamente privato di questo diritto.

Il diritto alla libertà di espressione - una "condizione indispensabile per il pieno sviluppo della persona", "essenziale per qualsiasi società" e "la pietra fondatrice per ogni società libera e democratica" secondo il Comitato per i diritti umani delle Nazioni Unite (2011: paragrafo 2) - è tutelato tramite le seguenti previsioni del diritto internazionale e regionale:

\section{Art. 19 della Dichiarazione universale dei diritti umani}

Ogni individuo ha diritto alla libertà di opinione e di espressione incluso il diritto di non essere molestato per la propria opinione e quello di cercare, ricevere e diffondere informazioni e idee attraverso ogni mezzo e senza barriere di frontiere.

\section{Art. 19 del Patto internazionale sui diritti civili e politici}

1. Ogni individuo ha diritto a non essere molestato per le proprie opinioni.

2. Ogni individuo ha il diritto alla libertà di espressione; tale diritto comprende la libertà di cercare, ricevere e diffondere informazioni e idee di ogni genere, senza barriere di frontiere, oralmente, per iscritto, attraverso la stampa, in forma artistica o attraverso qualsiasi altro mezzo di sua scelta.

3. L'esercizio delle libertà previste al paragrafo 2 del presente articolo comporta doveri e responsabilità speciali. Esso può essere pertanto 
sottoposto a talune restrizioni che però devono essere espressamente stabilite dalla legge ed essere necessarie:

a) al rispetto dei diritti o della reputazione altrui;

b) alla salvaguardia della sicurezza nazionale, dell'ordine pubblico, della sanità o della morale pubblica.

\section{Art. 20 del Patto internazionale sui diritti civili e politici}

1. Qualsiasi propaganda a favore della guerra deve essere vietata dalla legge.

2. Qualsiasi appello all'odio nazionale, razziale o religioso che costituisce incitamento alla discriminazione, all'ostilità o alla violenza deve essere vietato dalla legge.

\section{Art. 10 della Convenzione europea dei diritti dell'uomo}

1. Ogni persona ha diritto alla libertà d'espressione. Tale diritto include la libertà d'opinione e la libertà di ricevere o di comunicare informazioni o idee senza che vi possa essere ingerenza da parte delle autorità pubbliche e senza limiti di frontiera. Il presente articolo non impedisce agli Stati di sottoporre a un regime di autorizzazione le imprese di radiodiffusione, cinematografiche o televisive.

2. L'esercizio di queste libertà, poiché comporta doveri e responsabilità, può essere sottoposto alle formalità, condizioni, restrizioni o sanzioni che sono previste dalla legge e che costituiscono misure necessarie, in una società democratica, alla sicurezza nazionale, all'integrità territoriale o alla pubblica sicurezza, alla difesa dell'ordine e alla prevenzione dei reati, alla protezione della salute o della morale, alla protezione della reputazione o dei diritti altrui, per impedire la divulgazione di informazioni riservate o per garantire l'autorità e l'imparzialità del potere giudiziario.

\section{Art. 13 della Convenzione americana sui diritti umani}

1. Ognuno ha il diritto alla libertà di pensiero e di espressione. Tale diritto include la libertà di ricercare, ricevere e trasmettere informazioni e idee di ogni tipo, senza barriere di frontiera, oralmente o per iscritto, attraverso la stampa, in forma artistica o attraverso qualunque altro medium di propria scelta.

2. L'esercizio del diritto di cui al paragrafo precedente non sarà soggetto a censura preventiva, ma sarà motivo di responsabilità successiva, come stabilito espressamente dalla legge nella misura necessaria ad assicurare: 
a) il rispetto dei diritti e della reputazione di altri;

b) la protezione della sicurezza nazionale, dell'ordine pubblico o della salute o della morale pubblica.

3. Il diritto di espressione non può essere limitato con metodi o mezzi indiretti, quali l'abuso di controlli pubblici o privati sulla stampa periodica, sulle frequenze per le trasmissioni radio, o sulle strumentazioni per la diffusione dell'informazione, o con ogni altro mezzo che tenda ad impedire la comunicazione e la circolazione di idee e opinioni.

4. Nonostante quanto previsto nel paragrafo 2, gli spettacoli pubblici possono essere sottoposti da parte della legge a forme di censura preventiva al solo scopo di regolarne l'accesso per proteggere la morale dell'infanzia e dell'adolescenza.

5. Qualunque propaganda in favore della guerra e qualunque richiamo all'odio nazionale, razziale o religioso che costituisca incitamento alla violenza illegale o ad ogni altra azione simile contro qualunque persona o gruppo di persone per qualsiasi ragione, compresi motivi di razza, colore, religione, lingua o origine nazionale $o$ sociale, deve essere considerato dalla legge come reato.

\section{Art. 9 della Carta africana dei diritti dell'uomo e dei popoli}

1. Ogni persona ha diritto all'informazione.

2. Ogni persona ha il diritto di esprimere e diffondere le proprie opinioni nel quadro delle leggi e dei regolamenti.

Eventuali restrizioni alla libertà di espressione, inclusa la libertà dei giornalisti e degli operatori mediatici, possono essere imposte in circostanze specifiche. Qualsiasi restrizione alla libertà di espressione deve, in primis, essere prescritta o prevista dalla legge, in secundis, perseguire uno scopo legittimo, ovvero il rispetto dei diritti o della reputazione di altri, la protezione della sicurezza nazionale, dell'ordine pubblico, della salute o morale pubblica, nonché, in tertiis, essere necessaria per perseguire uno dei suddetti scopi legittimo e soddisfare il criterio di proporzionalità. Questo criterio si trova in tutti i trattati regionali in materia di diritti umani (come indicato precedentemente) e viene applicato dalle istituzioni internazionali e regionali che si occupano degli stessi. 


\subsection{Definizione di "giornalista"}

Nonostante i principali trattati internazionali e regionali in materia di diritti umani non considerino i giornalisti quale categoria di persone protette (a differenza del Protocollo aggiuntivo alla Convenzione di Ginevra del 12 agosto 1949 con riferimento alla protezione delle vittime di conflitti armati internazionali), le autorità internazionali regionali competenti tengono regolarmente conto della condizione di un individuo, per esempio quella di giornalista, nel determinare lo scopo e la natura degli obblighi dello Stato in relazione a tale persona derivanti dal diritto internazionale e regionale. La questione di "chi può essere considerato un giornalista?" è importante non solo in quanto determinati diritti e privilegi discendono dal titolo di "giornalista", bensì anche perché certi individui possono essere presi di mira o identificati in quanto svolgono tale ruolo (Heyns e Srinivasan 2013: 307). Rispondere oggi a tale domanda appare comunque difficile in considerazione dei cambiamenti in cui incorre il panorama mediatico. L'ascesa di internet negli ultimi due decenni ha radicalmente trasformato i media e la prassi giornalistica. I media dell'informazione si concentrano, infatti, più sulla promozione della loro pagina web che sul cartaceo, includendo i commenti e i contributi degli utenti ai testi dei giornalisti professionisti. Nuovi siti internet, bacheche informative online, blog e social network sono arrivati a dominare la divulgazione dell'informazione. In un clima del genere una crescente comunità di blogger e di c.d. "cittadini giornalisti" sono in grado di generare contenuti. ${ }^{24}$

In mancanza di una norma pattizia che definisca direttamente chi è un giornalista, le istituzioni internazionali e regionali in materia di diritti umani hanno adottato un approccio largamente funzionale, ma non identico, alla nozione. Nel suo rapporto del giugno 2012, il Rappresentante speciale per la libertà di opinione ed espressione, Frank La Rue, definisce i giornalisti utilizzando una nozione ampia, in relazione alla "loro funzione ed al loro servizio" in modo da includere "tutti gli operatori mediatici e lo staff di supporto, così come gli operatori mediatici della comunità e i c.d. 'cittadini giornalisti' quando svolgono momentaneamente tale funzione" (Consiglio per i diritti umani delle Nazioni Unite 2012b). Il Comitato per i diritti umani delle Nazioni Unite ha preferito focalizzarsi sulla prassi giornalistica piuttosto che sul ruolo del giornalista. Nel Commento generale $\mathrm{n}$.

24 In relazione ai principali andamenti globali e alle sfide relative a internet e alla libertà d'espressione, vedi: Comitato per i diritti umani delle Nazioni Unite (2011); Assemblea generale delle Nazioni Unite (2011). 
34 che interpreta gli obblighi degli Stati in base all'art. 19 del Patto internazionale sui diritti civili e politici, il Comitato asserisce che il giornalismo è "una funzione condivisa da una vasta gamma di soggetti, inclusi reporter professionisti a tempo pieno ed analisti, così come blogger ed altri che realizzano il loro impegno tramite forme di autopubblicazione a mezzo stampa, su internet o altrove ..." (Comitato per i diritti umani delle Nazioni Unite 2011: paragrafo 44). ${ }^{25}$ L'approccio del Comitato nei confronti del giornalismo è notevolmente più ampio dell'influente definizione di "giornalista" contenuta in una raccomandazione del Comitato dei Ministri del Consiglio d'Europa nel 2000, la quale definisce un giornalista "qualsiasi persona fisica o giuridica che lavora regolarmente o a titolo professionale nella raccolta e nella diffusione di informazioni al pubblico tramite qualsiasi mezzo di comunicazione di massa" (Comitato dei Ministri del Consiglio d'Europa 2000). È comunque interessante notare che nel 2011 il Comitato dei Ministri ha pubblicato una raccomandazione nella quale si invitano gli Stati membri "ad adottare una nuova, ampia nozione di media" per riconoscere che "il campo dei soggetti mediatici si è allargato come risultato dell'avvento delle nuove forme mediatiche nell'era digitale". Esso potrebbe includere i blogger a condizione che soddisfino determinati criteri. $^{26}$

A dispetto delle differenze e delle sovrapposizioni tra i vari significati attribuiti ai termini "giornalista", "giornalismo" e "media", vi è una forte convinzione che la protezione garantita dalle norme internazionali e regionali in materia di diritti umani ai giornalisti che sono oggetto di attacchi o minacce vada applicata anche agli operatori mediatici in senso più generale, in particolare a coloro che rivestono il ruolo di "guardiano pubblico" e che contribuiscono al pubblico dibattito o forniscono informazioni ad esso. A tal proposito, la "Dichiarazione sulla protezione del giornalismo e la sicurezza dei giornalisti ed altri attori mediatici" del 2014 del Comitato dei ministri del Consiglio d'Europa tratta i giornalisti ed altri attori mediatici allo stesso modo (Comitato dei ministri del Consiglio d'Europa 2014b: paragrafo 2).

In questa prospettiva, la dichiarazione si rifa alla posizione espressa dalla Corte europea dei diritti dell'uomo nella sentenza Táraság a Szabadságjogokért c. Ungheria, nella quale la Corte riconosce che il ruolo di "guardiano pubblico" viene ricoperto anche da altre figure nella società, oltre che dai

25 Per i commentari sui commenti generali, vedi Michael O'Flaherty (2012).

26 Vedi Comitato dei Ministri del Consiglio d'Europa (2011), in particolar modo il paragrafo 7. Vedi anche Comitato dei Ministri del Consiglio d'Europa (2014b). 
media. ${ }^{27}$ In questo caso, la Corte ha riconosciuto che è stato necessario applicare "la valutazione più prudente possibile [delle] misure adottate dall'autorità nazionale in grado di scoraggiare la partecipazione al pubblico dibattito in questioni di legittima rilevanza pubblica". ${ }^{28}$ Riconoscendo il "contributo importante della società civile alla discussione di pubblici affari”, un'organizzazione non-governativa coinvolta in, per inciso, contenziosi che attengono ai diritti umani, potrebbe servire ad informare il pubblico dibattito e costituire un "guardiano pubblico". ${ }^{29} \mathrm{La}$ Corte ha ritenuto che qualsiasi limitazione all'accesso a informazioni di pubblico interesse potrebbe dissuadere i giornalisti e gli operatori mediatici, ma anche coloro che "lavorano in campi collegati", dal continuare le proprie investigazioni e, di conseguenza, negare "il loro ruolo vitale di 'guardiani pubblici". ${ }^{30} \mathrm{Il}$ principio secondo il quale "un'organizzazione non-governativa coinvolta in questioni di pubblico interesse sta esercitando un ruolo di guardiano pubblico di importanza simile a quello della stampa" è stato ripetuto nei casi successivi Animal Defenders International c. Regno Unito e Youth Initiative for Human Rights c. Serbia. ${ }^{31}$ Oltre alle ONG, il Comitato per i diritti umani ha identificato altri soggetti che affrontano rischi simili a quelli dei giornalisti, in particolare coloro i quali "si impegnano nella raccolta e nell'analisi di informazioni sulle condizioni dei diritti umani e che pubblicano report legati agli stessi, inclusi i giudici e gli avvocati" (Comitato per i diritti umani delle Nazioni Unite 2011: paragrafo 23).

27 Corte Europea dei diritti dell'uomo, Társaság a Szabadságjogokért c. Ungheria, Ricorso n. 37374/05, Sentenza del 14 aprile 2009.

28 Ibid., paragrafi 26 e 27. Vedi anche Corte europea dei diritti dell'uomo, Bladet Tromsø and Stensaas c. Norvegia, Domanda N. 21980/83, Sentenza del 20 maggio 1999 (Grande camera), paragrafi 64; e Corte europea dei diritti dell'uomo, Jersild c. Danimarca, Ricorso N. 15890/89, 23 settembre 1994, paragrafo 35.

29 Ibid., paragrafo 27. Consultare anche Corte europea dei diritti dell'uomo, Steel and Morris c. Regno Unito, Ricorso n. 68416/01, Sentenza del 15 febbraio 2005 al paragrafo 89.

30 Ibid. Paragraph 38.

31 Corte europea dei diritti dell'uomo, Animal Defenders International c. Regno Unito, Ricorso n. 48876/06, Sentenza del 25 giugno 2013 al paragrafo 103; Corte europea dei diritti dell'uomo, Youth Initiative for Human Rights c. Serbia, Ricorso n. 48105/08, Sentenza della Grande Camera del 22 aprile 2013 al paragrafo 20. 


\subsection{L'importanza dei giomalisti per una società democratica}

Il nesso fondamentale tra la libertà di espressione, da un lato, e i valori democratici, dall'altro, è stato evidenziato in più occasioni da parte delle autorità per i diritti umani a livello internazionale e regionale. Il Comitato per i diritti umani ha espresso nel Commento generale n. 34 la propria visione secondo la quale la libertà di opinione e di espressione non sono solo "condizioni indispensabili per il pieno sviluppo della persona", bensì "essenziali per qualsiasi società" e "costituiscono il fondamento per qualsiasi società libera e democratica". ${ }^{32}$ Inoltre, secondo il Comitato, la libertà di espressione "è una condizione necessaria per la realizzazione dei principi di trasparenza e responsabilità che sono, a propria volta, essenziali per la promozione e la protezione dei diritti umani". ${ }^{33}$ Come statuito dalla Corte europea dei diritti dell'Uomo nel fondamentale caso Handyside c. Regno Unito nel 2016, "la libertà di espressione costituisce uno dei fondamenti essenziali per ... una società, una delle condizioni di base per il suo progresso e per lo sviluppo di ogni uomo". ${ }^{34}$ Dal canto suo la Corte interamericana dei diritti umani ha ripreso tale posizione nella propria Advisory Opinion del 1985 riguardante "L'iscrizione obbligatoria ad un'associazione prescritta dalla legge per la pratica del giornalismo", statuendo che la libertà di espressione è la "pietra miliare sulla quale si posa l'esistenza stessa di una società democratica" e che "è indispensabile per la formazione dell'opinione pubblica" (Corte interamericana dei diritti umani 1985: paragrafo 70). Di conseguenza "si può affermare che una società non adeguatamente informata non è una società veramente libera" (ibid.: paragrafo 70). ${ }^{35}$

Le autorità internazionali e regionali in materia di diritti umani hanno inoltre enfatizzato l'importanza della libertà di espressione per i media in numerose occasioni. Il Commento generale del Comitato per i diritti umani delle Nazioni Unite sottolinea l'importanza dei media, specialmente in riferimento alla cronaca politica. Il Comitato ha statuito che "una stampa libera [deve essere] in grado di commentare le tematiche pubbliche senza censure o restrizioni e di informare l'opinione pubblica" collegandola col

32 Ibid., paragrafo 2.

33 Ibid., paragrafo 3.

34 Corte europea dei diritti dell'uomo, Handyside c. Regno Unito, Ricorso n. 5493/72, Sentenza del 7 dicembre 1976 al paragrafo 49.

35 Vedi anche Corte interamericana dei diritti dell'uomo, Case of "The Last Temptation of Christ" (Olmedo Bustos ed altri) c. Chile, Sentenza del 5 febbraio 2001, paragrafo 68 . 
"diritto correlato [del pubblico] di ottenere un output mediatico" (Comitato per i diritti umani delle Nazioni Unite 2011: paragrafo 13). La Corte interamericana dei diritti umani ha poi enfatizzato tale posizione asserendo che "i giornalisti che lavorano nel settore mediatico dovrebbero godere della necessaria protezione e indipendenza in modo tale da poter esercitare appieno le loro funzioni, in quanto sono loro a tenere la società informata, un requisito indispensabile per consentire alla società di godere della piena libertà e affinché il pubblico discorso si rafforzi". 36

Gli attacchi a singoli giornalisti e operatori mediatici costituiscono, di conseguenza, attacchi alla funzione del giornalismo e quindi affievoliscono le possibilità di un pubblico dibattito in democrazia. Come statuito dalla Corte interamericana dei diritti umani nel caso Veléz Restrepo e famiglia c. Colombia, "il giornalismo può essere praticato liberamente soltanto quando coloro che esercitano tale mestiere non sono vittime di minacce o di attacchi fisici, psichici o morali o di altri atti di molestia". ${ }^{37}$ Mentre tali attacchi costituiscono anche la violazione dei loro diritti individuali alla libertà di espressione, interferiscono allo stesso tempo nel diritto degli altri individui nella società di ricercare e ottenere tutti i tipi di informazioni e idee (Commissione interamericana dei diritti umani 2008a: paragrafo 9). Asserito l'importante "ruolo sociale" di giornalisti e operatori mediatici, qualsiasi attacco contro di loro può essere ritenuto un attacco "alle fondamenta del progetto dei diritti umani e alla società informata per intero", come indicato dal Relatore speciale delle Nazioni unite sulle esecuzioni extragiudiziali, sommarie o arbitrarie, Cristof Heyns (Consiglio per i diritti umani delle Nazioni Unite2012c: paragrafo 24; Heyns e Srinivasan 2013: 306).

Non sorprende forse che la giurisprudenza delle corti regionali dei diritti umani si sia fino adesso focalizzata sull'importanza particolare dei media cartacei, essendo i media digitali un fenomeno relativamente recente. La Corte europea dei diritti dell'uomo ha parlato in numerose occasioni del "ruolo preminente della stampa in un Paese in cui vige lo stato di diritto" $\mathrm{o}$ in una società democratica nello specifico. ${ }^{38}$ Nella sentenza Jersild c. Danimarca, la Corte ha inoltre affermato che i media audiovisivi svolgono il

36 Corte interamericana dei diritti dell'uomo Il caso di Ivcher Bronstein c. Peru, Sentenza del 6 febbraio 2001, Serie C N. 74, paragrafo 150; Corte interamericana Il Caso di Herrera, Ulloa c. Costa Rica, Sentenza del 2 luglio 2004, Serie C N. 107, paragrafo 119.

37 Corte interamericana dei diritti dell'uomo, Vélez Restrepo e Famiglia c. Colombia, Sentenza del 3 settembre 2012, paragrafo 209.

38 Vedi per esempio, Corte europea dei diritti dell'uomo, MGN c. Regno Unito, Ricorso n. 39401/04, Sentenza del 18 gennaio 2001 al paragrafo 141; Corte europea 
ruolo di "'guardiano pubblico' vitale" e che hanno "un effetto molto più immediato e potente della carta stampata" ${ }^{39}$ Già da diversi anni la Corte ha riconosciuto che internet offre uno spazio per un dibattito aperto ai semplici cittadini così come ai giornalisti e "che nei tempi moderni sortisce effetti meno potenti dei media cartacei". ${ }^{40}$ Inoltre, nella sentenza Yildirim c. Turchia, la Corte europea dei diritti dell'uomo ha asserito che "internet è ora diventato uno dei principali mezzi tramite i quali gli individui esercitano il loro diritto alla libertà di parola e di informazione". ${ }^{41}$

\subsection{Gli obblighi positivi di protezione dei giornalisti}

Tutti i poteri dello Stato - esecutivo, legislativo e giudiziario - devono, a tutti i livelli - nazionale, regionale o locale -, adempiere a determinati obblighi al fine di assicurare il rispetto dei diritti umani all'interno della giurisdizione dello Stato. ${ }^{42}$ Le autorità dello Stato devono proteggere i diritti degli individui dall'interferenza arbitraria da parte di pubbliche autorità: uno Stato è responsabile di tutte le azioni e omissioni dei propri agenti nell'esercizio delle loro funzioni, a dispetto delle intenzioni degli agenti statali coinvolti. ${ }^{43}$ Vista in modo differente, uno Stato è responsabile delle violazioni attive e intenzionali dei diritti da parte di pubbliche autorità, così come del "sostegno o della tolleranza [delle violazioni] da parte delle pub-

dei diritti dell'uomo, Flux c. Moldovia, Ricorso n. 28702/03, Sentenza del 12 novembre 2007 al paragrafo 43; Corte europea dei diritti dell'uomo, Castells c. Spagna, Ricorso n. 11798/85, Sentenza del 23 aprile 1992 al paragrafo 43; Corte europea dei diritti dell'uomo, Thorgeir Thorgeirson c. Islanda, Ricorso n. 13778/88, Sentenza del 25 giugno 1992 al paragrafo 63.

39 Corte europea dei diritti dell'uomo, Jersild c. Danimarca, Ricorso n. 15890/8, Sentenza del 23 settembre 1994, paragrafo 31; Corte europea dei diritti dell'uomo, Observer and Guardianc. Regno Unito, Ricorso n. 13585/88, Sentenza del 26 novembre 1991, paragrafo 59; Corte europea dei diritti dell'uomo, The Sunday Times $c$. Regno Unito (n.2), Ricorso n. 13166/87, Sentenza del 26 novembre 1991, al paragrafo 50 .

40 Corte europea dei diritti dell'uomo, Fatullayev c. Azerbaigian, Ricorso n. 40984/05, Sentenza del 22 aprile 2010 al paragrafo 95.

41 Corte europea dei diritti dell'uomo, Yildirim c. Turchia, Ricorso n. 3111/10, Sentenza del 18 dicembre 2012 al paragrafo 54.

42 In relazione alla libertà di espressione, consultare Comitato per i diritti umani delle Nazioni Unite (2011), paragrafo 7.

43 Vedi in generale Corte europea dei diritti dell'uomo, research division (2011), nell'ambito della Convezione europea dei diritti dell'uomo. 
bliche autorità". ${ }^{44}$ In relazione del diritto alla vita ciò significa che la legge deve, come minimo, "controllare severamente e limitare le circostanze nelle quali una persona potrebbe essere privata della propria vita da parte di tali autorità" (Comitato per i diritti umani delle Nazioni Unite2003: paragrafo 3).

È, in ogni modo, fondamentale che gli Stati debbano anche intraprendere i passi necessari per assicurare la protezione effettiva dei diritti umani fra individui, includendo la prevenzione da interferenze nei diritti degli individui da parte di soggetti privati o non statali (Comitato per i diritti umani delle Nazioni Unite 2011: paragrafo 7; Commissione interamericana dei diritti umani 2013: 22). Di conseguenza, gli Stati possono "essere ritenuti responsabili di atti di individui privati" nel compimento dei loro obblighi internazionali legati ai diritti umani. ${ }^{45}$ La Corte europea dei diritti dell'uomo ha riconosciuto che uno Stato può essere legato a obblighi positivi $e x$ art. 2 della CEDU in modo da proteggere il diritto alla vita. Nella sentenza McCann ed altri c. Regno Unito, la Corte ha ritenuto che un divieto generale di omicidi arbitrari per gli agenti statali si è rivelato insufficiente per assicurare la protezione del diritto alla vita; gli obblighi che sorgono dalla CEDU richiedono anche "alcune forme di investigazioni ufficiali effettive quando individui sono stati uccisi conseguentemente all'uso della forza da parte di, inter alia, agenti dello Stato". ${ }^{46}$ Nella sentenza Osman c. Regno Unito, la Corte ha anche ritenuto che uno Stato è, come risultato dall'art. 2 della CEDU, tenuto a "intraprendere i passi opportuni in modo tale da salvaguardare le vite di coloro che si trovano all'interno della sua giurisdizione" mettendo in campo una struttura giudiziaria penale adeguata, incluse previsioni normative e "mezzi esecutivi per la prevenzione, la soppressione e la sanzione nel caso tali previsioni vengano infrante". ${ }^{47} \mathrm{Di}$ conseguenza, il diritto alla vita implicherebbe "un obbligo positivo per le auto-

44 Corte interamericana dei diritti dell'uomo, Case of the "Mapiripán Massacre" c. Colombia, Sentenza del 15 settembre 2005, Serie C N. 134, paragrafi 108-111; Corte interamericana dei diritti dell'uomo, Case of the "Pueblo Bello Massacre" c. Colombia, Sentenza del 31 gennaio 2006, Serie C n. 140, paragrafo 111.

45 Corte interamericana dei diritti dell'uomo, Case of the "Mapiripán Massacre" c. Colombia, Sentenza del 15 settembre 2005, Serie C n. 134, paragrafo 111-112; Corte interamericana dei diritti dell'uomo, Case of the "Pueblo Bello Massacre" c. Colombia, Sentenza del 31 gennaio 2006, Serie C N. 140, paragrafo 111. Vedi anche Corte interamericana dei diritti dell'uomo (2003: paragrafo 140).

46 Corte europea dei diritti dell'uomo, McCann ed altri c. Regno Unito, Ricorso n. 18984/91, Sentenza del 27 settembre 1995 (Grande Camera) al paragrafo 161.

47 Corte europea dei diritti dell'uomo, Osman c. Regno Unito, Ricorso n. 23452/94, Sentenza del 28 ottobre 1998 (Grand Chamber) al paragrafo 115. 
rità di intraprendere le misure operative di prevenzione per proteggere un individuo la cui vita è a rischio a causa degli atti criminosi di un altro individuo". 48

Nella sentenza Özgür Gündem c. Turchia, un caso che riguarda giornalisti e operatori mediatici schierati a favore del PKK, i quali sono stati l'obiettivo di una campagna di violenze e intimidazioni, la Corte europea dei diritti dell'uomo ha evidenziato l'importanza di misure positive per l'esercizio "reale" ed "effettivo" della libertà di espressione, così come considerazioni che attengono allo scopo di tali obblighi positivi per lo Stato. ${ }^{49}$ Gli obblighi positivi per lo Stato verranno discussi più avanti, specialmente in riferimento all'obbligo di protezione e prevenzione.

\subsection{Il riconoscimento degli effetti dell'impunità}

I Relatori speciali sulle esecuzioni extragiudiziali, sommarie e arbitrarie e sulla libertà di opinione ed espressione hanno evidenziato gli effetti dannosi che si producono quando si consente che gli attacchi ai giornalisti e agli operatori mediatici continuino in modo impunito, senza chiederne conto ai colpevoli. Il Relatore speciale sulle esecuzioni extragiudiziali, sommarie e arbitrarie, Christof Heyns, ha affermato che l'impunità è "ampiamente riconosciuta come una delle cause principali delle continue uccisioni di giornalisti" (Consiglio per i diritti umani delle Nazioni Unite 2012c: paragrafo 43). Il Relatore speciale per la promozione e la protezione del diritto alla libertà di opinione e di espressione, Frank La Rue, ha rilevato che l'impunità "incoraggia i perpetratori così come i potenziali aggressori ad attaccare i giornalisti senza alcuna conseguenza giuridica" e che essa rappresenta "una delle cause, se non la causa principale del numero inaccettabilmente alto di giornalisti attaccati o uccisi ogni anno" e che, così facendo, "genera ancora più violenza creando un circolo vizioso" (Consiglio per i diritti umani delle Nazioni Unite 2012b: paragrafo 65).

L'Impunità è stata definita dalla Corte interamericana dei diritti umani "l'assoluta carenza di investigazioni, ritrovamento, cattura, persecuzione e condanna dei responsabili della violazione dei diritti protetti dalla Con-

48 Ibid., paragrafo 115.

49 Corte europea dei diritti dell'uomo, Özgür Gündem c. Turchia, Ricorso n. 23144/93, Sentenza del 16 marzo 2000 al paragrafo 43. 
venzione americana". ${ }^{50}$ L'impunità quale conseguenza della "assenza di un'investigazione completa che porta alla condanna penale di tutti coloro che sono responsabili della morte di un giornalista" può, di per sé, anche essere considerata una violazione del diritto alla libertà di espressione "a causa dell'effetto intimidatorio che produce sull'impunità dei cittadini". ${ }^{51}$ Nel caso Vélez Restrepo e famiglia c. Colombia, la Corte interamericana dei diritti umani, seguendo la decisione della Commissione Interamericana, ha evidenziato che l'attacco contro il sig. Restrepo "da parte di soldati mentre stava riportando una manifestazione, nonché l'ampia diffusione della notizia nei media colombiani, ebbe un impatto negativo su altri giornalisti che stavano riportando eventi dello stesso tipo, i quali potrebbero temere simili atti di violenza". ${ }^{52}$ Oltre a sortire un "effetto paralizzante" su altri giornalisti, i fatti hanno altresì intimidito altri giornalisti dissuadendoli dall'esprimersi ed impedendo il libero flusso di informazioni riguardanti le forze armate che controllavano la manifestazione, le quali non poterono raggiungere i possibili destinatari, ovvero il pubblico. La Corte interamericana dei diritti umani ha ravvisato la violazione dell'art. 13 della Convenzione americana sui diritti umani in merito alla libertà di espressione. La violazione è dovuta, in parte, all'incapacità dimostrata dalle autorità statali colombiane nell'investigare in maniera effettiva gli atti di violenza commessi in precedenza contro il giornalista, ai quali si sono susseguente minacce e intimidazioni contro lo stesso. ${ }^{53}$

Adottando misure per "prevenire, investigare, identificare e punire" gli autori di violazioni dei diritti umani, gli Stati dovrebbero assicurare che vi siano adeguati ed effettivi meccanismi di trasparenza al fine di rompere un tale "circolo vizioso" di atti di violenza e combattere la cultura di impunità che circonda le violenze commesse contro i giornalisti. ${ }^{54}$ Secondo la Corte interamericana dei diritti umani, una rapida azione mirata alla punizione

50 Corte interamericana dei diritti dell'uomo, Constitutional Court c. Peru, 31 gennaio 2001, Serie C n. 71, paragrafo 123; Corte interamericana dei diritti dell'uomo, Bámaca Velásquez c. Guatemala, 25 novembre 2000, Serie C, n. 70, paragrafo 211.

51 Commissione interamericana dei diritti umani, Luis Gonzalo "Richard" Vélez Restrepo e famiglia c. Colombia, 23 ottobre 2010, paragrafo 136.

52 Corte interamericana dei ciritti umani, Vélez Restrepo e famiglia c. Colombia, Sentenza del 3 settembre 2012, paragrafo 148. Vedi anche Commissione interamericana dei diritti umani, Luis Gonzalo "Richard" Vélez Restrepo e famiglia c. Colombia, paragrafo136.

53 Corte interamericana dei ciritti umani, Vélez Restrepo e famiglia c. Colombia, paragrafo 215.

54 Corte interamericana dei ciritti umani, Ivcher-Bronstein c. Perú, Sentenza del 6 febbraio 2001, Serie C n. 74, paragrafo 186. 
di tutti gli autori è il modo in cui uno Stato può mandare "un segnale forte alla società che non vi sarà alcuna forma di tolleranza nei confronti di coloro che commettono una violazione del diritto alla libertà di espressione di tale gravità". 55

Il resto del presente capitolo tratta la natura degli obblighi degli Stati in relazione dei diritti umani al fine di rispondere agli attacchi ai giornalisti e agli operatori mediatici.

\section{UN RIEPILOGO DEGLI OBBLIGHI DEGLI STATI}

Gli Stati sono vincolati da una serie di obblighi di svolgere investigazioni, perseguire e punire nonché proteggere e prevenire gli attacchi ai giornalisti e agli operatori mediatici.

\subsection{L'obbligo di svolgere investigazioni, perseguire e punire}

\subsubsection{L'obbligo di svolgere investigazioni}

Considerazioni generali

Sulla base dell'art. 19 del Patto internazionale sui diritti civili e politici sulla libertà di espressione, nessun attacco alla persona, ivi inclusi l'arresto arbitrario, la tortura, minacce alla vita e uccisioni, può essere giustificato sulla base dell'esercizio, da parte della persona coinvolta, della propria libertà di espressione (Comitato per i diritti umani delle Nazioni Unite 2011: paragrafo 23). Quando tali attacchi si verificano, gli Stati hanno l'obbligo di "svolgere investigazioni in modo vigoroso in un lasso di tempo breve" tutti gli attacchi del genere commessi contro giornalisti ed operatori mediatici e di assicurare che "gli autori vengano processati, e che le vittime o, nel caso di uccisioni, i loro rappresentanti ricevano adeguate forme di ristoro", secondo il Comitato per i diritti umani delle Nazioni Unite nel Commento

55 Commissione interamericana dei diritti umani, Luis Gonzalo "Richard" Vélez Restrepo e famiglia c. Colombia, 23 ottobre 2010, paragrafo 136. Vedi anche Commissione interamericana dei diritti umani, Report n. 50/99. Caso 11.739, Héctor Félix Miranda c. Messico, 13 aprile 1999, paragrafo 52; Commissione interamericana dei diritti umani, Report n. 130/99, Caso n. 11.740, Victor Manuel Oropeza c. Messico, 19 novembre 1999 , paragrafo 58. 
generale n. 34 (ibid.). ${ }^{56}$ Il Consiglio per i diritti umani delle Nazioni Uniteha anche lanciato un appello agli "Stati affinché assicurino la trasparenza conducendo investigazioni imparziali, veloci ed effettive in tutti i presunti casi di violenza contro giornalisti e operatori mediatici che ricadono nella loro giurisdizione, consegnino alla giustizia gli autori dei fatti inclusi, inter alia, coloro che ordinano, pianificano, aiutano o coprono tali crimini alla giustizia ed assicurino che le vittime e le loro famiglie abbiano accesso a rimedi adeguati" (Consiglio per i diritti umani delle Nazioni Unite 2012a: paragrafo 4; 2014a: paragrafo 7).

Queste affermazioni, che colgono i principi fondamentali che disciplinano gli obblighi deli Stati di svolgere investigazioni in caso di attacchi ai giornalisti e agli operatori mediatici, discendono dal diritto internazionale e regionale, inclusa la giurisprudenza, che riguarda i c.d. "aspetti procedurali" del diritto alla vita così come il divieto di tortura e di trattamenti umilianti o disumani. ${ }^{57}$ Molti di questi principi sono ancorati nei "Principi sull'effettiva prevenzione ed investigazione di esecuzioni extralegali, arbitrarie o sommarie" raccomandati dal Consiglio economico e sociale delle Nazioni Unite nel 1989 (Consiglio economico e sociale delle Nazioni Unite 1989). Tali principi prevedono che le investigazioni di uccisioni extragiudiziali debbano essere "accurate, immediate e imparziali" e che siano condotte da soggetti indipendenti ( bid., nei principi 7 e 9). I procuratori dovrebbero agire in modo indipendente, imparziale e rapido (ibid., nel principio 5) ed altre autorità statali dovrebbero consentire ai procuratori di agire in modo indipendente e senza interferenza garantendo anche, qualora risultasse necessario, la loro sicurezza (ibid., nei principi 12 e 13).

Le autorità statali non dovrebbero attendere che la famiglia di un giornalista assassinato sporga denuncia prima di iniziare le investigazioni. Dovrebbero cominciare ad investigare d'ufficio non appena sono state informate dell'uccisione, in quanto tale compito rientra nei loro obblighi relativi al diritto alla vita. ${ }^{58}$ Inoltre, la responsabilità delle istituzioni di investigare in maniera completa ed accurata qualsiasi attacco contro un giornalista e di processare il responsabile dello stesso non dovrebbe essere negato dal fatto che in molti casi, se non nella maggior parte di essi, "la provenien-

56 Vedi anche Comitato per i diritti umani delle Nazioni Unite(2003); Ufficio dell'Alto Commissariato per i diritti dell'uomo delle Nazioni Unite (1989).

57 Gli Stati dovrebbero inoltre investigare sui casi di sparizione di giornalisti e lavoratori per i canali media che potrebbero comportare una violazione del loro diritto alla vita (Comitato per i diritti umani delle Nazioni Unite1982, paragrafo 4).

58 Corte europea dei diritti dell'uomo, Yaşa c. Turchia, Ricorso n. 22395/93, Sentenza del 2 settembre 1998 al paragrafo 100. 
za dell'atto di violenza potrebbe essere ignoto" e che potrebbe anche coinvolgere un soggetto privato, come evidenziato dal Relatore speciale delle Nazioni Unite sulla promozione e la protezione della libertà di opinione e di espressione nel 2012 (Consiglio per i diritti umani delle Nazioni Unite 2012b: paragrafo 56). La Corte interamericana dei diritti umani ha similmente notato che tale obbligo persiste per chiunque sia il presunto autore "in quanto, se sulle loro azioni non sono state svolte investigazioni in modo autentico, verrebbero, in un certo senso, aiutati dalle pubbliche autorità, il che implicherebbe la sussistenza di una responsabilità internazionale dello Stato". 59

La parte che segue contiene alcuni dei principi chiave che riguardano l'obbligo di svolgere investigazioni con riferimento specifico ai casi che riguardano gli attacchi ai giornalisti e agli operatori mediatici. Essi si verificano ogniqualvolta un giornalista o un operatore mediatico è stato ucciso oppure ha sofferto un maltrattamento quale risultato di un attacco commesso in violazione delle previsioni in materia di diritto alla vita ex art. 2 della CEDU o art. 4 della Convenzione americana sui diritti umani, o in violazione del divieto di tortura e di trattamenti disumani o umilianti o sanzioni, ex art. 3 della CEDU o art. 5 della Convenzione americana sui diritti umani, nel contesto del sistema dei diritti umani europeo o inter-americano. ${ }^{60}$ In tale contesto, la Corte ha ritenuto che il divieto di applicare trattamenti disumani o umilianti è stato violato nel caso di Tekin c. Turchia, nel quale un giornalista tenuto bendato in una cella fredda e buia è stato interrogato con la forza in modo tale da rilasciare ferite e lividi sul suo corpo. ${ }^{61}$

\section{Indipendenza}

Le autorità statali coinvolte nell'investigazione di attacchi ai giornalisti e nel procedimento contro gli autori dovrebbero essere autonome e indipendenti. In circostanze nelle quali sussiste il rischio di "influenza esagerata" da parte di altre autorità statali, incluso il governo, le investigazioni andrebbero "trasferite ad un'autorità differente al di fuori della loro giurisdi-

59 Corte europea dei diritti dell'uomo, Yaşa c. Turchia, Ricorso n. 22395/93, Sentenza del 2 settembre 1998 al paragrafo 100.

60 Corte europea dei diritti dell'uomo, Najafli c. Azerbaigian, Ricorso n. 2594/07, Sentenza del 2 ottobre 2012 al paragrafo 35.

61 Corte europea dei diritti dell'uomo, Tekin c. Turchia, Ricorso n. 22496/93, Sentenza del 9 giugno 1998 ai paragrafi 49-54. 
zione o sfera di influenza (per esempio, in casi adeguati, al livello federali in opposizione al livello statale" (Consiglio per i diritti umani delle Nazioni Unite 2012c: paragrafo 113). Nella Dichiarazione congiunta del 2012 si sottolinea che l'indipendenza significa "sia indipendenza gerarchica sia indipendenza istituzionale, così come le misure pratiche al fine di assicurare la stessa", un'affermazione che discende chiaramente dalla giurisprudenza della Corte europea dei diritti dell'uomo (Ufficio dell'Alto commissario delle Nazioni Unite per i diritti umani, 2012). ${ }^{62}$

La sicurezza nazionale e i processi e le corti militari non soddisfano il criterio di indipendenza quando includono la "presenza di un giudice militare la cui partecipazione dà luogo al timore legittimo che la corte potrebbe essere influenzata oltre misura per mezzo di considerazioni che nulla hanno a che vedere con la natura del caso", come ritenuto dalla Corte europea dei diritti dell'uomo nel già menzionato caso Kilic c. Turchia. ${ }^{63}$ In tale caso, la Corte ritenne che si trattò di "difetti [che] hanno indebolito l'effettività della protezione riconosciuta [al giornalista] dal diritto penale" e che "hanno incoraggiato la mancanza di responsabilità dei membri delle forze di sicurezza per le loro azioni, il che ... fu incompatibile con lo Stato di diritto in una società democratica che rispetta i diritti e le libertà garantiti dalla Convenzione". ${ }^{64}$ Similmente, la Corte interamericana dei diritti umani ha ribadito nel caso Vélez Restrepo e Famiglia c. Colombia la propria precedente giurisprudenza, dichiarando che il sistema di giustizia militare "non era il sistema competente per l'investigazione per il processo e la punizione degli autori delle violazioni dei diritti umani e soltanto i soldati in servizio attivo che hanno commesso crimini o reati minori che, in base alla loro natura, ledono beni giuridici di natura militare, possono essere processati dal sistema giudiziario militare". ${ }^{65}$

Le investigazioni di attacchi ai giornalisti da parte di agenti dello Stato (quali la polizia o altre forze di sicurezza dello Stato) devono essere svolte da parte di agenti dello Stato che operano per conto di un'altra pubblica autorità. Nel caso Najafli c. Azerbaigian, la Corte europea dei diritti dell'uo-

62 Vedi Corte europea dei diritti dell'uomo, Adal c. Turchia, Ricorso n. 38187/97, Sentenza del 31 marzo 2005, paragrafo222; Corte europea dei diritti dell'uomo, Ergi c. Turchia, Ricorso n. 23818/94, Sentenza del 28 giugno 1998, paragrafi 83-84.

63 Corte europea dei diritti dell'uomo, Kılıç c. Turchia, Ricorso n. 22492/93, Sentenza del 28 marzo 2000, paragrafo 74 .

64 Ibid., al paragrafo 75.

65 Corte interamericana dei diritti umani Vélez Restrepo e famiglia c. Colombia, questioni preliminari, merito, riparazioni e costi, Sentenza del 3 settembre 2012, Serie C n. 248, paragrafo 240. 
mo ha rilevato la violazione dell'art. 3 in merito al diritto di non essere oggetti ad un trattamento disumano o umiliante e dell'art. 10 in merito alla libertà di espressione. Si trattava del caso di un giornalista che stava riportando una manifestazione non autorizzata organizzata dall'opposizione a Baku. Nonostante il giornalista non stesse indossando il giubbotto blu che lo indentifica come appartenente alla stampa, stava comunque portando un tesserino che accertava la sua condizione di giornalista. Inoltre, ha più volte ripetuto ai propri aggressori poliziotti di essere un giornalista. ${ }^{66}$ Riaffermando il ruolo dei media, la Corte ha anche ritenuto che "riferire di assemblee e di manifestazioni dell'opposizione" è "essenziale per lo sviluppo di qualsiasi società democratica". ${ }^{67}$ Senza la possibilità di riportare tali eventi, "la stampa non sarebbe in grado di esercitare il proprio ruolo vitale di 'pubblico guardiano"”. ${ }^{68}$ In relazione agli obblighi procedurali dello Stato in base all'art. 3 CEDU, la Corte ha espressamente stabilito che "un investigazione condotta dalla polizia su accuse di cattiva condotta rivolte contro i suoi stessi ufficiali non è da considerarsi indipendente nel presente caso". ${ }^{69}$

\section{Celerità}

Come statuito nella Dichiarazione congiunta del 2012, le autorità dello Stato dovrebbero "intraprendere tutti gli accorgimenti necessari per velocizzare le investigazioni, incluso quello di agire non appena sono disponibili una denuncia ufficiale oppure prove affidabili in merito a un attacco contro la libertà di espressione" (Ufficio dell'Alto commissario delle Nazioni Unite per i diritti umani, 2012). Il Rappresentante speciale per le esecuzioni extragiudiziali, sommarie o arbitrarie ha promosso "I principi sull'effettiva prevenzione ed investigazione di esecuzioni extragiudiziarie, arbitrarie o sommarie" nel proprio rapporto del 2012 e sollecitato gli Stati ad adempiere il loro "obbligo di condurre investigazioni celeri ed esaustive in tutti i casi in cui si sospetta la violazione del diritto alla vita di giornalisti e di indentificare e di consegnare alla giustizia i responsabili" (Consiglio per i diritti umani delle Nazioni Unite 2012c: paragrafi 44, 111).

66 Corte europea dei diritti dell'uomo, Najfli c. Azerbaigian, Ricorso n. 2594/07, Sentenza del 2 ottobre 2012, ai paragrafi 64-65.

67 Ibid., al paragrafo 66.

68 Ibid., al paragrafo 66.

69 Ibid., al paragrafo 52. 
Un periodo di tre mesi intercorso tra la violazione e l'avvio dei passi iniziali procedurali rilevanti ha spinto la Corte europea dei diritti dell'uomo a ritenere che lo Stato avesse violato il proprio obbligo di svolgere un'investigazione effettiva seguendo gli aspetti procedurali dell'art. 3 della CEDU nel caso Najalfi c. Azerbaigian..$^{70} \mathrm{Nel}$ caso Héctor Felix Miranda c. Messico la Commissione interamericana dei diritti umani ha deciso che uno Stato aveva violato il proprio obbligo di condurre un'investigazione effettiva in quanto era passato più di un decennio senza che il mandante del reato fosse identificato e processato. ${ }^{71}$ Inoltre, non sussistevano giustificazioni per tale "durata prolungata senza ragioni dell'investigazione": la Commissione ha evidenziato che l'uccisione del giornalista Héctor Felix Miranda non fu "un caso estremamente complicato", dato che gli esecutori materiali vennero rapidamente processati e condannati e che vi furono prove univoche che rimandavano ad una mente potenziale. ${ }^{72} \mathrm{Nel}$ caso Vélez Restrepo e Famiglia c. Colombia, la Commissione interamericana ha osservato che erano passati 13 anni senza che lo Stato colombiano avesse identificato, processato o punito alcuno dei responsabili di una serie di minacce ed atti intimidatori nei confronti del giornalista Richard Velez ed i suoi familiari, atti che li costrinsero a lasciare il Paese. La Commissione ritenne che le investigazioni non erano state svolte in modo ragionevole e rilevò la violazione, da parte della Colombia, degli obblighi sanciti dall'art. 8, par. 1 della Convenzione americana sui diritti umani in merito al diritto al giusto processo. ${ }^{73}$ Le autorità dovrebbero svolgere le investigazioni rapidamente, evitando ritardi che potrebbero portare ad impunità e violare la protezione giudiziaria garantita dalla legge. ${ }^{74}$

70 Corte europea dei diritti dell'uomo, Najafli c. Azerbaigian, Ricorso n. 2594/07, Sentenza del 2 ottobre 2012, ai paragrafi 64-65.

71 Commissione interamericana dei diritti umani, Héctor Félix Miranda c. Messico, 13 aprile 1999, paragrafi 11, 30, 32.

72 Ibid., ai paragrafi 31 e 32.

73 Corte interamericana dei diritti umani, Gomez Palomino c. Peru, Sentenza del 22 novembre 2005, Serie C n. 136, paragrafo 85; Corte interamericana dei ciritti umani, Moiwana Community c. Suriname, Sentenza del 15 giugno 2005, Serie C n. 124, paragrafo 160 .

74 Corte interamericana dei ciritti umani, Case of G mez Palomino c. Peru Case. Merito, riparazioni e costi, Sentenza del 22 novembre 2005. Serie C n. 136, paragrafo 85 . 


\section{Effettività}

L'obbligo di svolgere investigazioni effettive significa che tali investigazioni debbano soddisfare determinati criteri, come indicato nella Dichiarazione congiunta del 2012 (Ufficio dell'Alto commissario delle Nazioni Unite per i diritti umani 2012). I criteri chiave per un'investigazione effettiva verranno analizzati in seguito.

In primo luogo, le investigazioni e i processi efficaci in risposta ad attacchi a giornalisti ed operatori mediatici richiedono che gli Stati siano politicamente impegnati nel combattere l'impunità in relazione a tali attacchi. Di conseguenza, gli Stati dovrebbero predisporre sufficienti risorse umane e finanziarie per raccogliere e analizzare le informazioni al fine di stabilire quali siano le responsabilità e assicurare che ne venga chiesto conto ai colpevoli. Il Relatore speciale delle Nazioni Unite sulla promozione e la protezione della libertà di opinione e di espressione ha raccomandato che "vengano dedicate le risorse necessarie alla prevenzione e all'investigazione degli attacchi e per consegnare i responsabili alla giustizia" (Consiglio per i diritti umani delle Nazioni Unite 2012b: paragrafo 102; 2012a: paragrafo $8(\mathrm{e})$ ). Il Relatore speciale sulle esecuzioni extragiudiziali, sommarie o arbitrarie si è espresso in maniera più specifica, raccomandando che "nei Paesi in cui si registrano molti attacchi contro i giornalisti, le investigazioni dovrebbero essere svolte da parte di unità investigative speciali che dispongano di sufficienti risorse e che siano adeguatamente addestrate per operare in modo efficiente ed efficace" (Consiglio per i diritti umani delle Nazioni Unite 2012c). La Dichiarazione congiunta nel 2012 evidenzia che "devono essere predisposte sufficienti risorse e possibilità di formazione al fine di assicurare che le investigazioni nei crimini contro la libertà di espressione siano accurate, rigorose ed effettive e che tutti gli aspetti di tali crimini vengano messi in luce in modo appropriato" (Ufficio dell'Alto commissario delle Nazioni Unite per i diritti umani 2012). È inoltre compito degli Stati "creare (eventualmente) unità investigative specializzate e dedicate all'uopo, con risorse a sufficienza ed una formazione adeguata al fine di operare in maniera efficiente ed efficace, per investigare sui crimini contro la libertà di espressione" (ibid.).

In secundis, qualsiasi investigazione di un attacco contro un giornalista che presenti limiti potrebbe essere ritenuta inefficace e di conseguenza suscettibile di violazione dei diritti umani. Nella sentenza Kiliçc. Turchia, la Corte europea dei diritti dell'uomo ha ritenuto che l'ambito limitato e la breve durata dell'investigazione dell'uccisione di un giornalista ha portato al fallimento dello svolgimento di un'investigazione, implicando la viola- 
zione degli aspetti procedurali dell'art. 2 della CEDU. ${ }^{75}$ La Corte ha affermato che vi furono una serie di inadeguatezze nell'investigazione, inclusa l'incapacità di chiarire se il giornalista fosse stato preso di mira mentre stava svolgendo il proprio lavoro per Özgür Gündem o circa la possibilità di "qualsiasi tipo di complicità con le forze di sicurezza nell'incidente". ${ }^{76}$

Terzo, qualsiasi investigazione in riferimento ad un attacco ad un giornalista dovrebbe essere svolta in maniera diligente e accurata, e dovrebbe esaminare come minimo i motivi degli autori seguendo un filo conduttore logico nelle inchieste. Le autorità dello Stato dovrebbero indagare sui motivi che soggiacciono all'attacco in modo tale da determinare se esso era rivolto contro l'attività professionale del giornalista. Nella sentenza Adali c. Turchia, la Corte europea dei diritti dell'uomo non ha ritenuto "non plausibile" che l'assassinio del giornalista critico nei confronti del governo "fosse avvenuto in collegamento con la sua attività giornalistica". ${ }^{77}$ La Corte ha comunque ritenuto che "le autorità non sono riuscite ad indagare sufficientemente sui motivi” che soggiacciono all'omicidio, inclusa l'incapacità di "investigare la possibilità che l'omicidio fosse avvenuto per ragioni politiche o collegato all'attività giornalistica" ${ }^{78} \mathrm{Al}$ contrario, sembrò che le "autorità responsabili avessero scartato tale ipotesi già in uno stadio precoce delle indagini e sulla base di prove insufficienti". Inoltre, "non furono condotte ricerche sugli scritti e su altri oggetti di proprietà del defunto al fine di trovare una qualsiasi prova che potesse fare luce sui motivi dell'assassinio". ${ }^{79}$

La Corte interamericana dei diritti umani ha posto l'accento sull'importanza di seguire un filo logico conduttore nelle investigazioni, collegando l'attività professionale dei giornalisti alla loro condizione di vittime di attacchi violenti. La Corte interamericana ha affermato che le investigazioni svolte da parte delle autorità statali dovrebbero riflettere "la complessità dei fatti, il contesto in cui sono occorsi ed i motivi sistematici che spiegano il motivo per il quale gli eventi si sono verificati", assicurando che non vi siano "alcune omissioni nella ricerca delle prove o nello sviluppo di un filo

75 Corte europea dei diritti dell'uomo, Kılıç c. Turchia, Ricorso n. 22492/93, Sentenza del 28 marzo 2000, paragrafo 83.

76 Ibid., al paragrafo 81-82.

77 Corte europea dei diritti dell'uomo, Adalı c. Turkey, Ricorso n. 38187/97, Sentenza del 31 marzo 2005, al paragrafo 231.

78 Ibid., al paragrafo 231.

79 Ibid., al paragrafo 231. 
conduttore logico delle indagini”. ${ }^{80} \mathrm{Nel}$ caso Manuel Cepeda Vargas c. Colombia la Corte interamericana dei diritti umani ha ritenuto che le autorità statali colombiane non erano riuscite a seguire un filo conduttore logico nelle investigazioni dell'omicidio di un giornalista e politico e che non erano state in grado di investigare le ipotesi e le schiaccianti prove che rimandavano alla mente dell'operazione criminale. ${ }^{81} \mathrm{Nel}$ caso Vélez Restrepo e famiglia c. Colombia la Corte ritenne, nel rilevare che le autorità statali non erano riuscite ad investigare seriamente sull'attacco contro un giornalista e le susseguenti minacce rivolte contro lo stesso e contro la sua famiglia, lo Stato avrebbe dovuto fare di più per prendere in considerazione "il ragionevole collegamento tra l'attacco, motivato dall'esercizio della libertà di espressione, ... e le susseguenti minacce e intimidazioni che si sono inasprite culminando in un tentativo di privazione della libertà". ${ }^{82}$ È interessante notare che la Corte ha evidenziato che il sig. Vélez Restrepo è stato malmenato mentre stava svolgendo il proprio lavoro e a causa dello stesso, un elemento che un'investigazione effettiva avrebbe senz'altro scoperto. ${ }^{83}$

Quarto, gli Stati hanno l'obbligo di assicurare che le investigazioni a seguito di attacchi contro un giornalista siano effettive, ovvero che siano in grado di concludersi con una decisione che determini se l'uso della forza fosse giustificato o meno a seconda delle circostanze e che identifichi e sanzioni i responsabili. ${ }^{84} \mathrm{Ciò} \mathrm{richiede} \mathrm{che} \mathrm{le} \mathrm{autorità} \mathrm{statali} \mathrm{intraprendano}$ un'attività di raccolta delle prove esauriente. Nella sentenza Gongadze c. Ucraina, un caso che riguardava l'assassinio di un giornalista politico, la Corte europea di diritti dell'uomo ha stabilito che ciò significa che "le autorità debbano aver intrapreso tutti i passi ragionevoli per assicurare le prove collegate al fatto" e che "[qualsiasi] lacuna nelle investigazioni che comprometta la possibilità di stabilire le cause del decesso o le persone responsabili ... rischierà di violare tale standard".$^{85}$

80 Corte interamericana dei ciritti umani, Rochela Massacre c. Colombia, Sentenza dell'11 maggio 2007, Serie C n. 163, paragrafo 158.

81 Corte interamericana dei ciritti umani, Manuel Cepeda-Vargas c. Colombia, Sentenza del 26 maggio 2010, Serie C n. 213, ai paragrafi 106-110, 167.

82 Corte interamericana dei ciritti umani, Vélez Restrepo and Family c. Colombia, questioni preliminari, merito, riparazioni e costi, Sentenza del 3 settembre 2012, Serie C n. 248, paragrafi 211 e 252.

83 Ibid., al paragrafo 142 .

84 Corte europea dei diritti dell'uomo, Dink c. Turchia, Ricorso n. 2668/07, 6102/08, 30079/08, 7072/09 e 7124/09, Sentenza del 14 settembre 2000, paragrafo 82-91.

85 Corte europea dei diritti dell'uomo, Gongadze c. Ucraina, Ricorso n. 34056/02, Sentenza dell'8 novembre 2005, paragrafo 176. 
Accesso agli atti delle indagini e ai processi

I parenti di un giornalista ucciso dovrebbero essere tenuti informati circa l'andamento delle investigazioni svolte dalle autorità dello Stato. Qualsiasi dossier investigativo dovrebbe essere messo a disposizione della famiglia, alla quale andrebbe regolarmente reso conto circa lo svolgimento ed i progressi svolti durante le investigazioni. La Dichiarazione congiunta del 2012 riconosce che alle vittime ed ai familiari dovrebbe essere "consentito un accesso effettivo" alle investigazioni ed ai relativi procedimenti, inclusa la condivisione dei documenti rilevanti con tali soggetti. Il sistema europeo e inter-americano dei diritti umani hanno consolidato tale standard, che è compreso nei "Principi sull'effettiva prevenzione ed investigazione di esecuzioni extralegali, arbitrarie o sommarie" (Consiglio economico e sociale delle Nazioni Unite 1989: sezione 16).

Nella sentenza Adali c. Turchia, la Corte europea dei diritti dell'uomo ha posto l'accento "sull'importanza di coinvolgere i familiari del deceduto o $\mathrm{i}$ loro rappresentanti legali nelle investigazioni e di fornire loro le informazioni così come di consentire loro di presentare ulteriori prove". ${ }^{86}$ La Corte ha ritenuto che la moglie di un giornalista "scomparso" avesse sofferto un trattamento umiliante in violazione dell'art. 3 della CEDU a causa dello stress emotivo provocato dall'atteggiamento e l'inattività delle autorità statali che stavano investigando sulla morte di suo marito. ${ }^{87}$ Alla moglie del giornalista era stato regolarmente rifiutato l'accesso alle informazioni contenute nel dossier del caso, consentendole di prenderne visione soltanto cinque anni dopo la scomparsa del marito. ${ }^{88}$ Gli Stati che rientrano nel sistema inter-americano dei diritti umani sono vincolati da un simile obbligo di assicurare che i parenti dei giornalisti uccisi abbiano pieno accesso in tutte le fasi e a tutti i livelli delle investigazioni e dei relativi processi, incluse le sanzioni ed i risarcimenti (Commissione interamericana dei diritti umani 2008a: paragrafo 41).

Curiosamente, la Dichiarazione congiunta del 2012 procede raccomandando che le organizzazioni della società civile dovrebbero essere in grado di partecipare attivamente ai reclami che riguardano crimini quali "l'omicidio, il rapimento o la scomparsa" di giornalisti e operatori mediatici, nello specifico "quando i parenti stretti non vogliono farlo o non ne sono in

86 Corte europea dei diritti dell'uomo, Adalı c. Turchia, Ricorso n. 38187/97, Sentenza del 31 marzo 2005, al paragrafo 232.

87 Corte europea dei diritti dell'uomo, Gongadze c. Ucraina, Ricorso n. 34056/02, Sentenza dell'8 novembre 2005, paragrafi 184-186.

88 Ibid., al paragrafo 185 . 
grado, e di intervenire nei [sic] procedimenti penali" (Ufficio dell'Alto commissario delle Nazioni Unite per i diritti umani 2012).

La protezione delle persone coinvolte

L'obbligo generale di investigare all'interno della cornice delle garanzie procedimentali obbligatorie comporta anche l'obbligo di proteggere coloro che sono coinvolti nelle investigazioni, ovvero le vittime, le loro famiglie, i testimoni, gli investigatori e i giudici da minacce o intimidazioni "mirate ad ostruire i procedimenti, impedire la soluzione dei fatti del caso ed evitare l'identificazione dei responsabili". ${ }^{89}$

Nel caso Vélez Restrepo e famiglia c. Colombia, la vittima e la sua famiglia furono minacciate e intimidite ripetutamente a causa della propria attività giornalistica e, in particolare, a causa della decisione di chiedere l'applicazione di sanzioni penali e disciplinari nei confronti delle forze di sicurezza statali che lo avevano attaccato in quanto stava riportando i loro abusi nei confronti di manifestanti disarmati. La Corte interamericana dei diritti umani ha ritenuto la Colombia responsabile di aver fallito nell proteggere il sig. Vélez Restrepo e la sua famiglia, un fallimento che ha poi spinto la vittima ed i suoi familiari a fuggire dal Paese..$^{90}$ La Corte è giunta ad una conclusione simile nel caso Manuel Cepeda Vargas c. Colombia, nel quale ha ritenuto che i familiari della vittima, un giornalista e politico colombiano assassinato da persone appartenenti alle forze armate, fossero minacciati con lo scopo di evitare che gli autori dovessero rendere conto del loro operato, costringendo i familiari ad andare in esilio. ${ }^{11}$

Le giornaliste donne

Dal punto di vista di genere, la Corte interamericana dei diritti umani ha ritenuto che, nel caso di attacchi contro le donne, incluse le giornaliste donne, è "particolarmente importante che le autorità responsabili delle in-

89 Corte interamericana dei ciritti umani, Rochela Massacre c. Colombia, Sentenza dell'11 maggio 2007, Serie C n. 163, paragrafo 171.

90 Corte interamericana dei ciritti umani, Vélez Restrepo e famiglia c. Colombia, questioni preliminari, merito, riparazioni e costi, Sentenza del 3 settembre 2012, Serie C n. 248, paragrafi 203-204.

91 Corte interamericana dei ciritti umani, Manuel Cepeda-Vargas c. Colombia, Sentenza del 26 maggio 2010, Serie C N. 213, paragrafi 194-195. 
vestigazioni le svolgano ... in modo determinato ed effettivo, tenendo presente l'obbligo, per la società, di respingere la violenza contro le donne e l'obbligo, per lo Stato, di eliminarla e di assicurare che le vittime confidino nelle istituzioni dello Stato per la loro protezione". ${ }^{92}$ La Corte interamericana ha anche evidenziato gli obblighi specifici per gli Stati di investigare le accuse di stupro che potrebbero essere rilevanti per comprendere l'ambito degli obblighi per lo Stato in relazione agli atti di violenza sessuale commessi contro i giornalisti, indipendentemente se uomini o donne. ${ }^{93}$

\subsubsection{L'obbligo di procedere e di punire}

Le norme sulla prescrizione

Le norme sulla prescrizione non dovrebbero rappresentare ostacoli alla ricerca di giustizia per i giornalisti e gli operatori mediatici che hanno perso le loro vite, sono stati feriti o minacciati. Il Rappresentante speciale sulle esecuzioni extragiudiziali, sommarie o arbitrarie raccomanda che le "norme sulla prescrizione non dovrebbero consentire di fermare i processi" (Consiglio per i diritti umani delle Nazioni Unite 2012c: paragrafo 111). Similmente, la Dichiarazione congiunta del 2012 prevede che "i crimini contro la libertà di espressione, e il crimine di ostruzione alla giustizia in relazione a tali crimini, dovrebbero essere soggetti o a normative che non pongono termini di prescrizione oppure i termini contenuti nelle normative dovrebbero essere estesi (p.es. il tempo oltre il quali i procedimenti sono vietati)" (Ufficio dell'Alto commissario delle Nazioni Unite per i diritti umani 2012), mentre il Piano di azione delle Nazioni Unite sulla sicurezza dei giornalisti e sul problema dell'impunità richiede agli Stati membri di adempiere in toto al "principio secondo il quale non vi dovrebbe essere alcuna limitazione in riferimento a persone colpevoli di crimini contro la libertà di espressione" (UNESCO 2013: paragrafo 5.9; 1997).

92 Corte interamericana dei ciritti umani, Rosendo Cantú et al. c. Messico, Sentenza del 31 agosto 2010, Serie C n. 216, paragrafo 177.

93 Ibid., al paragrafo 178 . 
La proporzionalità della pena

Tramite i loro testi ufficiali e i loro rapporti, le organizzazioni internazionali che si occupano di diritti umani hanno ripetuto che vanno svolte investigazioni accurate sugli attacchi contro i giornalisti e che gli autori di tali attacchi debbano essere processati (per esempio, Consiglio per i diritti umani delle Nazioni Unite 2012b: paragrafo 98; 2012c: paragrafo 70). Tali organizzazioni non hanno ancora approfondito in generale la questione delle pene appropriate per gli attacchi ai giornalisti come tali (Consiglio per i diritti umani delle Nazioni Unite 2012a, 2103). La Dichiarazione congiunta del 2012 statuisce, in ogni caso, che tali crimini debbano essere "previsti dal diritto penale, o in maniera esplicita o come circostanza aggravante che comporti pene più severe per tali crimini, tenendo conto della gravità della loro natura", e che debbano soddisfare il requisito della proporzionalità (Ufficio dell'Alto commissario delle Nazioni Unite per i diritti umani 2012).

In base ai principi consolidati del diritto internazionale, qualsiasi pena prevista per coloro che sono stati giustamente condannati per omicidi e attacchi non mortali nei confronti di giornalisti e operatori mediatici dovrebbe certamente essere proporzionata. Secondo il Gruppo di lavoro sulla detenzione arbitraria un individuo può essere privato del proprio diritto alla libertà sancito dall'art. 9 del Patto internazionale sui diritti civili e politici solo nella misura necessaria per soddisfare un'esigenza urgente della società, e in maniera proporzionata a tale bisogno (Commissione per i diritti umani delle Nazioni Unite 2005: paragrafo 63; Consiglio per i diritti umani delle Nazioni Unite 2014c: paragrafo 72). Questo principio chiave di condanna significa che ogni sentenza pronunciata sulla base di un attacco contro un giornalista o un operatore mediatico debba essere "commisurata al reato commesso". La Corte europea dei diritti dell'uomo ha affermato che la proporzionalità è una parte essenziale della sentenza e ha tenuto fermo che, in casi eccezionali, una sentenza "esageratamente sproporzionata" potrebbe essere ritenuta lesiva delle disposizioni contenute nell'art. 3 della CEDU. ${ }^{94}$ La rilevanza del principio di proporzionalità nella sentenza è stata evidenziata anche dalla Corte interamericana dei diritti umani. Nella sentenza Rochela Massacre c. Colombia, la Corte ha ritenuto che gli stati

94 Corte europea dei diritti dell'uomo, Harker and Edwards c. Regno Unito, Ricorso n. 32650/07, Sentenza del 17 gennaio 2012, al paragrafo 134; vedi anche Corte europea dei diritti dell'uomo, Rrapo c. Albania, Ricorso n. 58555/10, Sentenza del 25 settembre 2012, al paragrafo 90. 
debbano, al fine di adempiere i loro obblighi di investigare, processare, punire e di prevedere un ristoro per serie violazioni dei diritti umani, garantire "il giusto processo garantire i principi di celerità della giustizia, del contraddittorio, del ricorso effettivo, di esecuzione della sentenza, e di proporzionalità della pena, oltre ad altri principi" ${ }^{95}$ La Corte ha proseguito affermando che la pena prevista per un crimine "dovrebbe essere proporzionata ai diritti riconosciuti dalla legge e alla colpevolezza con la quale ha agito l'autore, che dovrebbe essere valutata a sua volta quale funzione della natura e della gravità degli eventi $[$ sic $] "{ }^{96}$

\section{Riparazioni}

I giornalisti e gli operatori mediatici vittime di attacchi dovrebbero ricevere un risarcimento o un ristoro adeguato per le minacce o per la violazione del loro diritto alla vita o alla libertà di espressione. Tale principio è ampiamente supportato dalle organizzazioni internazionali che si occupano di diritti umani (Comitato per i diritti umani delle Nazioni Unite 2011: paragrafo 23; Consiglio per i diritti umani delle Nazioni Unite 2012c: paragrafo 43; 2012a: paragrafo 7). Nel caso Velásquez Rodríguez c. Honduras, la Corte interamericana dei diritti umani ha ritenuto che gli Stati non solo devono "prevenire, investigare e punire qualsiasi violazione dei diritti", devono anche "tentare di risarcire il diritto violato e prevedere un indennizzo per i danni che scaturiscono dalla violazione". ${ }^{97}$

La Dichiarazione congiunta del 2012 afferma che le riparazioni devono includere un ristoro economico così come il reinserimento, ed le riparazioni civili dovrebbero essere disponibili indifferentemente dal fatto che vi fosse o meno una condanna per un reato contro la libertà di espressione. Nelle circostanze in cui è presente una condanna per un reato contro la libertà di espressine, vi dovrebbe essere un "sistema ... in modo tale da assicurare che si provveda ad una riparazione adeguata per le vittime, senza che esse debbano proporre azione separata". Oltre ad essere proporzionati, i rimedi "dovrebbero includere un ristoro economico, ed una serie di misure volte a reinserire le vittime e a facilitare il loro ritorno nelle loro case

95 Corte interamericana dei ciritti umani, Rochela Massacre c. Colombia, Sentenza dell'11 maggio 2007, Serie C n. 163, paragrafo 193.

96 Ibid., al paragrafo 196.

97 Corte interamericana dei ciritti umani, Velásquez Rodr guez c. Honduras, Sentenza del 29 luglio 1988, Serie C n. 04, paragrafo 166. 
in condizioni di sicurezza" (Ufficio dell'Alto commissario delle Nazioni Unite per i diritti umani 2012).

La gamma di riparazioni previste dalla Corte interamericana dei diritti umani in casi di attacchi contro i giornalisti è tipica dell'approccio positivo di tale corte regionale nel garantire gli indennizzi. Si consideri che la Corte, nel caso Vélez Restrepo e famiglia c. Colombia, ha ordinato allo Stato, oltre che a svolgere un'adeguata investigazione penale ed a pagare un risarcimento per il danno patrimoniale e non, a: garantire le condizioni necessarie affinché i membri della famiglia Vélez Román possano ritornare a vivere in Colombia, qualora lo volessero; "provvedere all'assistenza sanitaria delle vittime per mezzo dei propri istituti sanitari se le vittime hanno manifestato la loro intenzione di tornare in Colombia"; pagare alle vittime somme di denaro al fine di aiutarle a coprire i costi dei trattamenti sanitari qualora i membri della famiglia Vélez Román decidessero di non tornare a vivere in Colombia; e, ciò che è di maggior interesse, "inserire nei propri programmi formativi in materia di diritti umani per le forze armate un modulo specifico per la protezione del diritto alla libertà di pensiero e di espressione e sul ruolo dei giornalisti e dei comunicatori sociali".$^{98}$ Nella sentenza Manuel Cepeda Vargas c. Colombia, la Corte interamericana dei diritti umani ha anche ordinato allo Stato di adottare tutte le misure necessarie per garantire la sicurezza della famiglia di Manuel Cepeda e per evitare che essa debba trasferirsi o lasciare il Paese in conseguenza delle minacce o atti di intimidazione o di persecuzione che potrebbero seguire la sentenza stessa, pubblicare le parti chiave della sentenza su un sito web adeguato del Paese, organizzare un "atto pubblico di riconoscimento della responsabilità internazionale per i fatti del caso in questione", preparare insieme alla famiglia e diffondere una pubblicazione e creare un documentario audiovisivo sulla vita politica, la carriera giornalistica e il ruolo politico del Senatore Manuel Cepeda Vargas; e provvedere alle cure mediche e psicologiche di cui le vittime necessitano." 99

98 Corte interamericana dei ciritti umani, Vélez Restrepo e famiglia c. Colombia, questioni preliminari, merito, riparazioni e costi, Sentenza del 3 settembre 2012, Serie C n. 248, paragrafo 317.

99 Corte interamericana dei ciritti umani, Manuel Cepeda-Vargas c. Colombia, Sentenza del 26 maggio 2010, Serie C n. 213, al paragrafo 265 (paragrafi del dispositivo). 


\subsection{L'obbligo di protezione}

L'obbligo di proteggere i giornalisti e gli operatori mediatici discende dagli obblighi positivi degli Stati in relazione al diritto alla vita così come dal diritto alla libertà di espressione. A norma del diritto internazionale in materia di diritti umani, tale obbligo richiede agli Stati di proteggere i giornalisti e gli altri operatori mediatici dalle minacce di soggetti non-statali, specialmente se essi sono stati identificati quali particolari potenziali vittime di un attacco (Comitato per i diritti umani delle Nazioni Unite 2004). Secondo il Comitato per i diritti umani delle Nazioni Unite, gli Stati sono obbligati a "mettere in campo misure effettive di protezione dagli attacchi finalizzati a silenziare coloro che esercitano il loro diritto alla libertà di espressione" (Comitato per i diritti umani delle Nazioni Unite 2011: paragrafo 23).

La Dichiarazione congiunta del 2012 prevede che "una serie di misure protettive, che dovrebbero essere adattate a seconda delle circostanze individuali della persona a rischio", andrebbero attuate "qualora sussista il rischio continuato e grave che vengano commessi crimini contro la libertà di espressione" (Ufficio dell'Alto commissario per i diritti umani delle Nazioni Unite 2012). Importanti esperti dell'ONU hanno evidenziato il significato di "misure particolari" quali mezzi di protezione nei loro rispettivi rapporti. Il Relatore speciale per la libertà di opinione e di espressione ha raccomandato che "le misure particolari andrebbero messe in campo al fine di contrastare gli attacchi e di aiutare i giornalisti rifugiatisi a causa di questi” e il Relatore speciale sulle esecuzioni extragiudiziali, sommarie o arbitrarie ha esortato "gli Stati in cui si registrano uccisioni schematiche di giornalisti" a "intraprendere misure particolari per contrastare tale fenomeno" (Consiglio per i diritti umani delle Nazioni Unite 2012b: paragrafo 102; 2012c: paragrafo 112). Inoltre, il Piano di azione ONU ha anche richiamato gli Stati ad "intraprendere azioni immediate in risposta agli attacchi creando meccanismi di emergenza nazionali adottabili dai vari stakeholder" (UNESCO 2012: 5.8). Una serie di programmi speciali già esistenti per la protezione di giornalisti, così come le misure necessarie per metterli in campo laddove non esistono nella regione OSA (nello specifico, in Colombia, Messico, Brasile, Guatemala e nell'Honduras), sono state presentate dal rapporto importante del 2013 del Relatore speciale OSA per la libertà di espressione sulla Violenza contro giornalisti e operatori mediatici: Standard Inter-Americani e pratiche nazionali di prevenzione, protezione e procedimento penale contro gli autori (Commissione Interamericana dei Diritti Umani 2013: 55-98). 
In particolare, il Consiglio per i diritti umani delle Nazioni Unite, "tiene conto", nella propria risoluzione più recente in materia, delle "buone pratiche" esistenti "nei vari Stati" e invita gli Stati a "sviluppare ed adottare strategie per combattere l'impunità di attacchi e violenza", quali "la creazione di unità investigative speciali o commissioni indipendenti", "la nomina di un procuratore speciale", "l'adozione di protocolli e metodi di investigazione e di processo penale specifici", "la creazione di sistemi di ricerca di informazioni, quali banche dati" e la creazione di un meccanismo di avvertimento precoce e di risposta rapida in modo tale da offrire ai giornalisti, quando vengono minacciati, accesso immediato alle autorità e alle misure protettive (Consiglio per i diritti umani delle Nazioni Unite 2014a: paragrafi 4-5). La neocreata "Piattaforma per la promozione della protezione del giornalismo e della sicurezza dei giornalisti” del Consiglio d'Europa può sicuramente essere considerata un meccanismo di protezione regionale per avvertire le istituzioni rilevanti.

La giurisprudenza regionale sugli obblighi positivi per gli Stati è rilevante per determinare le circostanze nelle quali andrebbero messe in campo le misure protettive. Nella sentenza Kiliç c. Turchia, un caso che riguarda l'omicidio di un giornalista che aveva in precedenza richiesto l'adozione di misure protettive da parte delle autorità statali per sé stesso e per altri soggetti, la Corte europea dei diritti dell'uomo ha ritenuto che, per verificare se vi fosse stata una violazione dell'obbligo positivo, andava appurato se:

le autorità sapevano o avrebbero dovuto sapere al tempo dell'esistenza di un rischio reale e immediato per la vita di un determinato individuo o di individui da parte di atti criminosi di un terzo e se non sono riuscite a intraprendere misure rientranti nei loro poteri attuabili, da un punto di vista ragionevole, per contrastare tale rischio. ${ }^{100}$

La Corte ha ritenuto che Kemal Kiliç fosse esposto, in quanto giornalista, al rischio di un attacco "immediato e reale", che le autorità fossero a conoscenza di tale rischio e che fossero, in aggiunta, "consapevoli, o avrebbero dovuto esserlo, della possibilità che tale rischio derivasse dalle attività di persone o gruppi che agivano con la consapevolezza o con il consenso di soggetti delle forze di sicurezza." 101 Dopo aver affermato che lo Stato turco "non era stato in grado di adottare le misure ragionevoli ... per prevenire un rischio reale e immediato per la vita di Kemal Kiliç”, la Corte stabilì che

100 Corte europea dei diritti dell'uomo, Kılıçc. Turchia, Ricorso n. 22492/93, Sentenza del 28 marzo 2000, paragrafo 63.

101 Ibid., ai pragrafi 66-68. 
vi era stata una violazione dell'art. 2 della CEDU. ${ }^{102} \mathrm{Nel}$ valutare se lo Stato non era stato in grado di adempiere il proprio obbligo di proteggere la vita di un giornalista "sapendo che la sua incolumità era a rischio", la Corte europea dei diritti dell'uomo ha tenuto conto della misura in cui tali persone, in particolare i procuratori, "dovrebbero essere consapevoli della posizione vulnerabile in cui un giornalista il quale ha affrontato tematiche politicamente sensibili si è posto difronte a coloro che detengono il potere in quel momento storico". ${ }^{103}$ La Corte europea dei diritti dell'uomo non ha tenuto conto, nella sentenza Kiliç c. Turchia, delle rimostranze mosse dalla prospettiva dell'art. 10 della CEDU, comunque, sulla base del fatto che proveniva dallo stesso fatto delle rimostranze fondate sull'art. 2, del quale la Corte ha ravvisato la violazione. ${ }^{104}$

La Corte ha comunque ravvisato sia la violazione dell'art. 2 che dell'art. 10 della CEDU nel caso più importante da lei deciso in materia di protezione e sicurezza dei giornalisti, il caso Dink c. Turchia. Il caso riguardava l'omicidio di Harant Dink, un giornalista turco ed direttore di un settimanale turco-armeno. L'articolo a firma di Dink sull'identità dei cittadini turchi di origine armena aveva in precedenza suscitato reazioni aggressive da parte di nazionalisti estremi che avevano organizzato manifestazioni, scritto lettere intimidatorie e anche sporto denuncia penale contro di lui, ritenuto alla fine colpevole. La Corte ha ritenuto che le forze di sicurezza turche possano essere ragionevolmente considerate informate circa le forti ostilità manifestate contro il giornalista negli ambienti nazionalisti estre$\mathrm{mi}$, che le autorità di law-enforcement fossero al corrente della probabilità di un tentativo di omicidio contro il giornalista e addirittura dell'identità dei probabili istigatori, cosicché la minaccia di un assassinio fosse reale e imminente. Nonostante tutti questi fattori, le autorità turche non furono in grado di adottare le misure ragionevoli per proteggere la vita di Dink. (Secondo l'opinione della Corte, nonostante Dink non avesse richiesto maggiori misure protettive, avrebbe potuto non essere a conoscenza del piano per assassinarlo.). La Corte ha ritenuto che la decisione delle corti turche, le quali hanno dichiarato Dink colpevole di aver denigrato l'identità turca, ha costituito di per sé o in combinazione con la mancanza di misure protettive per il giornalista un'interferenza con il suo diritto alla libertà di espressione. La Corte ha ritenuto che la sua condanna, con la qua-

102 Ibid., al paragrafo 77.

103 Corte europea dei diritti dell'uomo, Gongadze c. Ucraina, Ricorso n. 34056/02, Sentenza dell'8 novembre 2005, paragrafi 166 e 168.

104 Corte europea dei diritti dell'uomo, Kılıç c. Turchia, Ricorso n. 22492/93, Sentenza del 28 marzo 2000, paragrafo 87. 
le Dink è stato punito per aver scritto alcuni articoli critici col mancato riconoscimento, da parte dello Stato, del genocidio degli armeni del 1915, tematiche di importante interesse pubblico e oggetto di dibattito in una società democratica, non corrispondesse a un" urgente esigenza sociale" e fosse, di conseguenza, non necessaria in una società democratica. Vista l'incapacità delle autorità dello Stato di proteggere Dink dagli attacchi di gruppi nazionalisti estremi e la condanna in assenza di un'esigenza sociale urgente, lo Stato non è stato in grado di adempiere i propri obblighi positivi in relazione alla libertà di espressione. ${ }^{105}$ In tale contesto, la Corte ha ritenuto che gli Stati dovrebbero assicurare la presenza di un clima positivo per l'esercizio di tale diritto. Ovvero:

Gli stati sono tenuti a creare un ambiente favorevole per la piena partecipazione di tutti i soggetti coinvolti al dibattito pubblico, consentendo loro l'espressione di opinioni e idee senza timore, anche quando esse contrastano con quelle sostenute dalle autorità o di una parte importante dell'opinione pubblica nonché quando vengono considerate offensive o scandalose. ${ }^{106}$

La Corte interamericana dei diritti umani ha adottato un approccio simile a quello della Corte Europea nella sentenza Kiliçc. Turchia nel caso Pubelo Bello Massacre c. Colombia per determinare quando viene infranto l'obbligo positivo dello Stato di proteggere la vita. ${ }^{107}$ Nella sentenza Vélez Restrepo e famiglia c. Colombia, la Commissione Interamericana dei diritti umani ha ritenuto che lo Stato non fosse stato in grado di proteggere un giornalista e la sua famiglia da una serie di minacce che lo hanno poi costretto a lasciare il Paese. Nello specifico, la Commissione ha concluso che lo Stato colombiano non aveva adottato "in maniera diligente e nei tempi giusti le misure necessarie per proteggere il sig. Vélez e la sua famiglia dalle minacce e dagli attacchi posti all'attenzione della autorità" e che, di conseguenza, "la violazione dell'integrità fisica e morale del sig. Vélez e dei suoi congiunti è attribuibile allo Stato per aver omesso di adottare effettivi mezzi di protezione nonostante fosse stato informato e reso consapevole dei rischi che

105 Corte europea dei diritti dell'uomo, Dink c. Turchia, Ricorsi n. 2668/07, 6102/08, 30079/08, 7072/09 e 7124/09, Sentenza del 14 settembre 2000, paragrafi 64-75, 106-108, 137-138 (Francia).

106 Ibid., al paragrafo 137.

107 Corte interamericana dei diritti umani, "Pueblo Bello Massacre" c. Colombia, Sentenza del 31 gennaio 2006, Serie C n. 140, paragrafo 124, citando la Corte europea dei diritti dell'uomo, Kulıc c. Turchia, Ricorso n. 22492/93, Sentenza del 28 marzo 2000, paragrafo 63. 
correvano il giornalista e la sua famiglia". ${ }^{108}$ La Corte interamericana ha condiviso le conclusioni della commissione. In particolare, ha ritenuto che "gli Stati hanno l'obbligo di adottare speciali misure di prevenzione e protezione per i giornalisti soggetti a rischi particolari collegati all'esercizio della loro professione" nonché fattori quali "le tipologie di eventi coperti, il pubblico interesse nei confronti delle informazioni che diffondono, o i luoghi in cui devono recarsi per svolgere il loro mestiere". 109

Nel caso del giornalista Vélez Restrepo, la Corte interamericana ha concluso che egli "affrontava chiaramente un rischio reale e immediato per la propria integrità personale" e che lo Stato, nonostante fosse a conoscenza di tale situazione, non era stato in grado di agire diligentemente nell'adottare le necessarie misure di protezione per il giornalista e la sua famiglia in modo tempestivo. ${ }^{110} \mathrm{La}$ Corte ha posto l'accento sul fatto che le autorità statali avrebbero dovuto familiarizzare con "la situazione di rischio particolare al fine di determinare o valutare se la persona al centro delle minacce e delle intimidazioni richiedesse misure di protezione o se riferire del caso all'autorità competente affinché assumesse i provvedimenti all'uopo necessari ed anche informare tempestivamente la persona a rischio circa le misure disponibile". ${ }^{111} \mathrm{~A}$ fronte dei passi intrapresi da parte delle autorità statali colombiane per proteggere i giornalisti a rischio, la Corte ha esortato la Colombia a "continuare a intraprendere tutte le misure necessarie da adottare e a rafforzare i programmi speciali per proteggere i giornalisti in pericolo". ${ }^{112}$

\subsection{L'obbligo di prevenzione}

\subsubsection{Considerazioni generali}

Gli obblighi di prevenire attacchi sono strettamente collegati, e si sovrappongono, a quelli di proteggere i giornalisti da attacchi e violenze, in particolare in contesti in cui le autorità sono a conoscenza, o avrebbero dovuto

108 Commissione interamericana dei diritti umani, Vélez Restrepo and Family c. Colombia, Report n. 136/10 Caso 12.658, 23 ottobre 2010.

109 Corte interamericana dei diritti umani, Vélez Restrepo and Family c. Colombia, questioni preliminari, merito, riparazioni e costi, Sentenza del 3 settembre 2012, Serie C n. 248, paragrafo 194.

110 Ibid., al paragrafo 194.

111 Ibid., ai pragrafi 209, 194, 195, 197, 201 e 203.

112 Ibid., ai paragrafi 289 e 290. 
esserlo, della presenza di un rischio reale e immediato che un giornalista o un operatore mediatico possano diventare vittime di un attacco. Come indicato dalla Corte europea dei diritti dell'uomo nella sentenza Gongadze c. Ucraina, gli obblighi di uno stato "[si protraggono], in circostanze appropriate, fino all'obbligo positivo, per le autorità, di adottare misure operative precauzionali al fine di proteggere uno o più individui le cui vite sono $\mathrm{a}$ rischio a causa di atti criminali di un altro soggetto". ${ }^{113}$ La Corte interamericana dei diritti umani ha altresì ritenuto che una strategia preventiva dovrebbe tenere conto ed affrontare le sfide che riguardano le donne in particolare. La Corte ha stabilito che una tale strategia dovrebbe "prevenire i fattori rischio e, al contempo, rafforzare le istituzioni che possono fornire una risposta adeguata in caso di atti di violenza contro le donne." ${ }^{114}$ Sulla base di tali prospettive, l'assenza di una policy pubblica generale di prevenzione e l'incapacità di tenere conto dei fattori rischio che colpiscono le giornaliste donne possono significare che lo Stato non è stato in grado di adempiere il proprio obbligo di prevenzione. ${ }^{115}$

La Dichiarazione congiunta del 2012 contiene una parte considerevole in cui sono state elaborate misure giuridiche e non che andrebbero intraprese al fine di adempiere l'obbligo di prevenire i reati contro la libertà di espressione "quando sussiste il rischio che essi si concretizzino e in situazioni specifiche in cui le autorità sono a conoscenza, o avrebbero dovuto esserlo, dell'esistenza di un rischio reale e immediato che vengano commessi tali crimini, e non solo qualora i soggetti a rischio richiedano misure protettive da parte dello Stato". Mentre la Dichiarazione congiunta sollecita la creazione di un tipo specifico di "reati contro la libertà di espressione" quale misura protettiva, volge, allo stesso tempo, l'attenzione sulle misure preventive non giuridiche, ovvero:

I. andrebbe fornita una formazione adeguata nel campo dei reati contro la libertà di espressione, inclusi i reati di genere, alle istituzioni il cui compito consiste nel far rispettare la legge, incluse le forze di polizia ed i P.M., così come, qualora risultasse necessario, alle forze armate;

II. andrebbero sviluppati e adottati manuali e linee guida per le istituzioni, il cui compito consiste nel far rispettare la legge, qualora essi vengano a contatto con reati contro la libertà di espressione;

113 Corte europea dei diritti dell'uomo, Gongadze c. Ucraina, Ricorso n. 34056/02, Sentenza dell'8 novembre 2005, paragrafo 164.

114 Corte interamericana dei ciritti umani, González et al. ("Campo di cotone") c. Messico, quesitoni preliminari, merito, riparazioni e costi, Sentenza del 16 novembre 2009, Serie C n. 205, paragrafo 258.

115 Ibid., al paragrafo 282. 
III. gli individui che potrebbero diventare vittime di reati contro la libertà di espressione dovrebbero poter fruire di corsi formativi organizzati dallo Stato. Inoltre, tali argomenti andrebbero affrontati nei corsi di laurea che riguardano il giornalismo e le scienze delle comunicazioni;

IV. andrebbero messi in campo sistemi per assicurare un accesso effettivo alle informazioni riguardanti le circostanze, le investigazioni e i processi dei reati contro la libertà di espressione, incluso l'accesso dei media ai tribunali, a fronte di adeguate garanzie di riservatezza; e

V. si dovrebbe considerare di mettere in campo misure generali di protezione, come p.es. fornire assistenza sanitaria, una copertura assicurativa o altri benefici a favore degli individui che potrebbero essere vittime di reati contro la libertà di espressione (Ufficio dell'Alto commissario delle Nazioni Unite per i diritti umani 2012: paragrafo 2c).

Il Piano di azione ONU prende ampiamente in considerazione i "meccanismi di prevenzione e le azioni al fine di affrontare alcune delle cause che si pongono alla radice delle violenze contro i giornalisti e dell'impunità". Esso include misure per affrontare la corruzione e la criminalità organizzata, così come "leggi che limitano la libertà di espressione (p.es. leggi troppo restrittive in materia di diffamazione)" (UNESCO 2012: paragrafo 1.6). Esorta gli Stati "a svolgere un ruolo attivo nella prevenzione degli attacchi contro i giornalisti, e a reagire immediatamente agli attacchi creando meccanismi di emergenza nazionali" (UNESCO 2012: paragrafo 5.8).

I seguenti capitoli evidenziano i vari elementi chiave dell'obbligo di prevenire.

\subsubsection{Favorire un clima di prevenzione}

Gli Stati dovrebbero in primis favorire, all'interno della società, la creazione di un clima favorevole alla prevenzione degli attacchi contro i giornalisti e gli operatori mediatici. Un tale clima può essere promosso in diversi modi.

Crimini contro la libertà di espressione

Come precedentemente indicato, gli Stati dovrebbero creare una specifica categoria di reati contro la libertà di espressione al fine di utilizzare il potere dissuasivo della legislazione penale per prevenire atti di violenza contro 
i giornalisti. La Dichiarazione congiunta del 2012 raccomanda che "le categorie di reati contro la libertà di espressione andrebbero fatte rientrare nell'ordinamento penale, in modo esplicito o quali circostanze aggravanti che comportano pene più severe per tali crimini, in considerazione della gravità della loro natura" (Ufficio dell'Alto commissario delle Nazioni Unite per i diritti umani 2012). Tale raccomandazione risente della Risoluzione UNESCO 29, la quale richiama gli Stati a "raffinare la legislazione al fine di rendere possibile processare e condannare coloro che istigano l'assassinio di persone le quali esercitano il loro diritto alla libertà di espressione" (UNESCO 1997).

\section{Denunciare}

I pubblici ufficiali dovrebbero utilizzare la loro libertà di espressione in senso positivo al fine di "condannare in modo inequivocabile gli attacchi commessi come rappresaglia per l'esercizio della libertà di espressione e dovrebbero astenersi dall'esprimere affermazioni che potrebbero aumentare la vulnerabilità di coloro che diventano bersagli per aver esercitato il loro diritto alla libertà di espressione" (Ufficio dell'Alto commissario delle Nazioni Unite per i diritti umani 2012). Dovrebbero inoltre tenere conto di una rapida e severa condanna degli attacchi commessi contro i giornalisti e operatori mediatici quale aspetto del loro dovere di punire i responsabili, ma anche del loro obbligo di prevenzione. ${ }^{116}$ Come raccomandato dal Relatore speciale sulle esecuzioni extragiudiziali, sommarie o arbitrarie, "va attuato un chiaro supporto pubblico nei più alti livelli di governo per condannare le esecuzioni extragiudiziali, sommarie o arbitrarie dei giornalisti e le minacce alle loro vite, e per rimarcare l'importanza del ruolo dei giornalisti della società" (Consiglio per i diritti umani delle Nazioni Unite 2012c: paragrafo 110), un'impostazione condivisa anche dal Commissario per i diritti umani del Consiglio d'Europa (2011: prefazione).

Nella sentenza Perozo et al c. Venezuela, la Corte interamericana dei diritti umani ha considerato gli attacchi agli impiegati di un'emittente televisiva a causa delle affermazioni rese da un alto pubblico ufficiale, secondo il quale l'emittente, il suo proprietario e i dirigenti sono "nemici della rivoluzione", "nemici del popolo venezuelano", "fascisti" e partecipi al colpo di

116 Corte interamericana dei ciritti umani, Rios et al. c. Venezuela, questioni preliminari, merito, riparazioni e costi, Sentenza del 28 gennaio 2009, Serie C n. 194, paragrafo 151 . 
stato contro il Presidente Hugo Chavéz avvenuto nel 2002. ${ }^{117}$ I pubblici ufficiali goderebbero certamente della libertà di espressione, ma essa andrebbe esercitata con particolare cautela in situazioni sociali sensibili. Trovandosi i pubblici ufficiali "in una posizione di garanti dei diritti fondamentali", "le loro espressioni non possono essere tali da disprezzare detti diritti, cosicché essi non possono arrivare a interferire o a fare pressioni riducendo i diritti di coloro che desiderano contribuire alle scelte pubbliche". Tale particolare "obbligo di speciale cautela si accresce nelle situazioni di grandi conflitti sociali, condotte disordinate o faziosità sociali e politiche". ${ }^{118}$

\section{Educazione e formazione}

Gli Stati dovrebbero assicurare che i principali pubblici ufficiali ricevano un'adeguata educazione e formazione in merito alla protezione dei giornalisti. I Relatori speciali ONU e OSA hanno affermato che "un'adeguata formazione delle forze di sicurezza dello Stato sul ruolo della stampa in una società democratica rappresenta un passo importante per la prevenzione della violenza contro i giornalisti e gli operatori mediatici in situazioni agitazione sociale" (ONU e OSA 2013). Secondo la Dichiarazione congiunta del 2012, mentre le forze di "law-enforcement" e gli ufficiali dell'esercito dovrebbero fruire di programmi di educazione e formazione adeguati, inclusi "manuali operativi e linee guida", nei "reati contro la libertà di espressione, inclusi i reati di genere", coloro "che potrebbero diventare vittime" di tali reati dovrebbero avere accesso a misure formative offerte dallo Stato, e i corsi universitari in giornalismo e scienze delle comunicazioni dovrebbero altresì affrontare tale tematica (Ufficio dell'Alto commissario delle $\mathrm{Na}$ zioni Unite per i diritti umani 2012).

Per quanto concerne la sentenza Vélez Restrepo e famiglia c. Colombia, la Corte interamericana dei diritti umani ha apprezzato "le misure intraprese dalla Colombia ... per mezzo di direttive che cercano di aumentare la consapevolezza, all'interno delle Forze armate, sul lavoro dei giornalisti e dei comunicatori sociali e dei pericoli che essi affrontano, specialmente durante conflitti armati, e anche sul rispetto necessario che essi devono mantene-

117 Corte interamericana dei ciritti umani, Perozo et al. c. Venezuela, questioni preliminari, Sentenza del 28 gennaio 2009, Serie C n. 195, paragrafi 141-142, 139.

118 Ibid., ai pragrafi 141-142, 151. 
re affinché possano esercitare la loro professione senza ostacoli". ${ }^{119}$ Nondimeno, ha ordinato allo Stato colombiano di "inserire nel programma educativo sui diritti umani per le forze armate un modulo specifico sulla protezione del diritto alla libertà di opinione e espressione e sul lavoro dei giornalisti e dei comunicatori sociali”. ${ }^{120}$

\section{Ricerca di informazioni}

Al fine di proteggere gli individui, ma anche di prevenire attacchi futuri, gli Stati dovrebbero creare e conservare "statistiche dettagliate e separate" sugli attacchi contro i giornalisti e gli operatori mediatici così come "la persecuzione di tali reati" (Ufficio dell'Alto commissario delle Nazioni Unite per i diritti umani 2012). Una tale ricerca di informazioni da parte dello Stato sugli omicidi e sulle minacce contro i giornalisti e gli operatori mediatici andrebbe affiancata da sforzi simili da parte di organizzazioni intergovernative e non governative, e dovrebbe "analizzare le tendenze e gli sviluppi, inclusa la modalità sensibile di genere" (Consiglio per i diritti umani delle Nazioni Unite 2012c: paragrafo 107).

\section{Giornaliste donne}

La particolare vulnerabilità e " $\mathrm{i}$ rischi specifici affrontati dalle giornaliste donne nell'esercizio della loro professione" comportano che gli Stati debbano adottare un approccio sensibile alle esigenze di genere quando pianificano le misure per garantire la sicurezza dei giornalisti, così come ribadito dal Consiglio per i diritti umani delle Nazioni Unite (2013b: paragrafo 3). Un tale "approccio sensibile alle esigenze di genere" è stato sostenuto anche dal Relatore speciale per la promozione e la protezione del diritto alla libertà di opinione e di espressione (Consiglio per i diritti umani delle Nazioni Unite 2012b: paragrafo 52). L'educazione e i programmi formativi dovrebbero, di conseguenza, servire a contrastare gli stereotipi di genere sulle giornaliste donne e le operatrici mediatiche, le quali potrebbero essere particolarmente esposte a determinati tipi di attacchi (Commissione in-

119 Corte interamericana dei ciritti umani, Vélez Restrepo e famiglia c. Colombia, questioni preliminari, merito, riparazioni e costi, Sentenza del 3 settembre 2012, Serie C n. 248, paragrafo 277.

120 Ibid., al paragrafo 317. 
teramericana dei diritti umani 2011: paragrafo 181). Il crescente fenomeno degli attacchi online contro le giornaliste donne ed altre comunicatrici evidenza la necessità di una risposta a tali attacchi di genere, in particolare tramite, tra l'altro, formazioni sensibili alle problematiche di genere nelle scuole di giornalismo, così come misure per combattere la misoginia nella società in generale.

\subsubsection{Un ambiente per $i$ media liberi}

Dalla prospettiva della libertà di espressione, gli Stati dovrebbero andare oltre la prevenzione degli attacchi contro i giornalisti e gli operatori mediatici i quali potrebbero correre rischi da tali attacchi: dovrebbero "altresì [creare] un ambiente in cui i media indipendenti, liberi e plurali possano prosperare e i giornalisti non corrano il rischio di essere arrestati" (Consiglio per i diritti umani delle Nazioni Unite 2012b: paragrafo 78). In termini di cornice giuridica, dovrebbero essere presenti due caratteristiche chiave affinché un tale ambiente possa esistere: in primis, i giornalisti non dovrebbero essere costretti a rivelare le loro fonti, e, in secundis, non dovrebbero essere puniti col reato di diffamazione.

\section{La confidenzialità delle fonti}

Mentre il Comitato per i diritti umani promuoveva questo "limitato privilegio giornalistico di non rivelare le fonti informative" tramite il Commento generale n. 34 a livello internazionale (Consiglio per i diritti umani delle Nazioni Unite 2011: paragrafo 45), è stato anche evidenziato in numerose occasioni, da parte degli organismi regionali del Consiglio d'Europa, ${ }^{121}$ della Commissione Africana sui diritti dell'uomo e dei popoli (Commissione africana sui diritti dell'uomo e dei popoli 2002: XV), e dalla Commissione interamericana dei diritti umani (2000: principio 8). Il "diritto dei giornalisti di non rivelare le loro fonti salvo che in circostanze molto dettagliatamente definite" è importante per la protezione dei giornalisti e degli operatori mediatici così come delle loro fonti da eventuali attacchi. ${ }^{122}$ Come

121 Vedi, per esempio, Comitato dei Ministri del Consiglio d'Europa (2000); Assemblea Parlamentare del Consiglio d'Europa (2011).

122 Comitato per i Diritti Umani delle Nazioni Unite (2012c) al paragrafo 59, riferendosi all'Assemblea Parlamentare del Consiglio d'Europa (2005, 2007a, 2010). 
recentemente osservato dall'Ufficio del Relatore speciale OSA per la libertà di espressione, "la protezione di fonti confidenziali non contribuisce soltanto al ruolo fondamentale della stampa di pubblico guardiano, ma aiuta anche a prevenire che i giornalisti divengano vittime di violenze" (Commissione interamericana dei diritti umani 2013: paragrafo 54). L'imposizione dell'obbligo, nei confronti di un giornalista, di rilevare le proprie fonti o addirittura la percezione che sussista un tale obbligo "non solo ne limita la possibilità di accedere a fonti informative, ma aumenta il rischio di finire nel mirino di gruppi violenti", ${ }^{123}$ in particolare in situazioni di tensione sociale (ONU e OSA 2013).

La protezione di fonti giornalistiche è stata ritenuta prioritaria da parte della Corte europea dei diritti dell'uomo in quanto "una delle condizioni base per la libertà di stampa" in seguito al fondamentale caso Goodwin c. Regio Unito. In tale caso, la Corte ha statuito che:

Senza una tale protezione, le fonti potrebbero astenersi dal sostenere la stampa nell'informare il pubblico su argomenti di pubblico interesse. $\mathrm{Ne}$ conseguirebbe che il ruolo vitale di pubblico guardiano svolto dalla stampa potrebbe indebolirsi e la capacità della stampa di fornire informazioni accurate e affidabili sarebbe compromessa. In considerazione dell'importanza della protezione delle fonti giornalistiche per la libertà di stampa in una società democratica e del potenziale effetto distorsivo che l'imposizione di rivelare tali fonti potrebbe esercitare su tale libertà, una misura del genere non può ritenersi compatibile con l'art. 10 della Convenzione senonché quand'essa sia giustificata da un'esigenza preminente di pubblico interesse. ${ }^{124}$

Tale protezione è "parte e frazione del diritto all'informazione" più che un "mero privilegio da garantire o da sottrarre a seconda della legittimità o illegittimità delle fonti". ${ }^{125}$ Qualsiasi imposizione con la quale si richiede la rivelazione delle fonti giornalistiche deve essere giustificata dall'interesse pubblico. Se quest'ultimo non sussiste, essa "avrà un impatto dannoso non soltanto sulla fonte in questione, la cui identità potrebbe essere rivelata, ma anche sul giornale nei confronti del quale l'imposizione è diretta, la cui reputazione potrebbe essere pregiudicata negli occhi di potenziali fonti future per mezzo della rilevazione e sul pubblico, il quale è interessato a rice-

123 Corte europea dei diritti dell'uomo, Goodwin c. Regno Unito, Ricorso n. 17488/90, Sentenza del 27 marzo 1996, paragrafo 39.

124 Ibid.

125 Corte europea dei diritti dell'uomo, Tillack c. Belgio, Ricorso n. 20477/05, Sentenza del 27 novembre 2007, paragrafo 65. 
vere informazioni ottenute tramite fonti anonime e che è a sua volta una potenziale fonte". ${ }^{126}$ Nella sentenza Sanoma Uitgevers BV c. Paesi Bassi, la Grande Camera della Corte europea dei diritti dell'uomo ha evidenziato che gli ordini con i quali si richiede ai giornalisti di rivelare le loro fonti devono essere soggetti alla garanzia di controllo giudiziario o controllati da parte di un altro organo di controllo indipendente e imparziale. ${ }^{127} \mathrm{La}$ Corte ha ritenuto che la circostanza che un ordine di rivelazione abbia portato, o meno, all'effettiva rivelazione o alla persecuzione delle fonti giornalistiche per stabilire l'esistenza di una violazione dei diritti garantiti ai giornalisti dall'art. 10 della CEDU, in quanto "l'effetto intimidatorio sorgerà ogniqualvolta $\mathrm{i}$ giornalisti vengono visti come ausilio per l'identificazione di fonti anonime". ${ }^{128}$

La Corte europea dei diritti dell'uomo ha anche riconosciuto che la sorveglianza segreta da parte dello Stato può interferire contro la libertà di espressione del singolo se sussiste il rischio che le comunicazioni giornalistiche vengano monitorate, in quanto ciò potrebbe significare che le fonti potrebbero essere rilevate o scoraggiate a fornire informazioni per telefono. La trasmissione di dati ad altre autorità, la loro distruzione o l'incapacità di informare il giornalista delle misure di sorveglianza potrebbe altresì pregiudicare la confidenzialità delle fonti. ${ }^{129}$

\section{Il reato di diffamazione}

Le normative sul reato di diffamazione sono considerate, in aggiunta agli attacchi violenti contro $i$ giornalisti, una delle side chiave verso la libertà di espressione da parte di autorità intergovernative che operano in riferimento alla medesima libertà di espressione (Consiglio per i diritti umani delle

126 Corte europea dei diritti dell'uomo, Financial Times Ltd ed altri c. Regno Unito, Ricorso n. 821/03, Sentenza del 15 dicembre 2009, paragrafo 63.

127 Corte europea dei diritti dell'uomo, Sanoma Uitgevers BV c. Olanda, Ricorso n. 38224/03, Sentenza della Grande camera del 9 settembre 2010.

128 Ibid., 71.

129 Corte europea dei diritti dell'uomo, Weber and Saravia c. Germania, Ricorso n. 54934/00, decisione di ammissibilità del 29 giugno 2006, paragrafo 145. In relazione alla questione della sorveglianza, vedi anche la Corte europea dei diritti dell'uomo, Bucur and Toma c. Romania, Ricorso n. 40238/02, Sentenza dell'8 gennaio 2013, in cui la Corte rilevò una violazione dell'art. 10 nel caso di un infiltrato che fu sanzionato (con una pena, sospesa, pari a 2 anni di reclusione) per aver rilevato ai media informazioni relative ai servizi di intelligence sulla sorveglianza di giornalisti, politici e importanti uomini d'affari. 
Nazioni Unite 2010: paragrafo 2; Commissione interamericana dei diritti umani 2009: paragrafo 55). Il Relatore speciale sulla libertà di opinione ha più volte espresso la propria preoccupazione "in merito alla continua esistenza e all'uso di leggi penali contro i giornalisti e i membri dei media, le quali vengono spesso utilizzate dalle autorità per sopprimere informazioni 'scomode' e per evitare che i giornalisti affrontino tematiche simili in futuro", riguarda in particolare modo l'interesse pubblico. L'inviato ha consigliato la depenalizzazione dei reati di diffamazione ovunque, sulla base del fatto che esse "sono rigide per natura ed esercitano un effetto sproporzionalmente scoraggiante sulla libertà di espressione" (Consiglio per i diritti umani delle Nazioni Unite 2012b: paragrafi 79 e 105). Inoltre, le sanzioni economiche per l'illecito civile della diffamazione "deve essere severamente proporzionato al danno causato e limitato dalla legge" (ibid.: paragrafi 79 e 106). La diffamazione dovrebbe riguardare soltanto la legislazione civile e non il diritto penale, così come previsto dal Piano di azione dell'ONU (UNESCO 2012: punto 5.9). L'Assemblea parlamentare del Consiglio d'Europa ha anche esortato gli Stati membri ad abolire le pene detentive per la diffamazione senza ritardi (Assemblea parlamentare del Consiglio d'Europa 2007b).

Mentre il Comitato per i diritti umani delle Nazioni Unite e la Corte europea dei diritti dell'uomo non hanno ritenuto che le leggi penali in materia di diffamazione vadano abrogate in quanto tali, le circostanze in cui tali organismi le considerano accettabili sono molto circoscritte. Nel Commento generale n. 34, il Comitato per i diritti umani delle Nazioni Unite ha esortato gli Stati a prendere in considerazione la depenalizzazione della diffamazione, statuendo che "l'applicazione del diritto penale dovrebbe essere consentita solo nei casi più gravi e la pena detentiva non rappresenta mai un rimedio adeguato" Inoltre, secondo il Comitato, uno Stato non dovrebbe "incriminare una persona sulla base del reato di diffamazione, ma poi non procedere con il processo in tempi rapidi in quanto una tale pratica sortisce un effetto scoraggiante che potrebbe eccessivamente restringere l'esercizio della libertà di espressione della persona coinvolta e di altri soggetti" (Consiglio per i diritti umani delle Nazioni Unite 2011: paragrafo 47).

Nonostante la Corte europea dei diritti dell'uomo abbia affermato che le sanzioni penali per il reato di diffamazione non siano necessariamente sproporzionate, essa terrà conto dell'imposizione delle stesse in considera- 
zione della questione della proporzionalità. ${ }^{130}$ Le pene detentive producono per la loro "natura ... un effetto dissuasivo sull'esercizio della libertà giornalistica". ${ }^{131}$ Di conseguenza, "l'imposizione di una condanna penale per un illecito di stampa sarà compatibile con la libertà di espressione del giornalista garantita dall'art. 10 della Convenzione soltanto in circostanze eccezionali, in particolare qualora siano stati seriamente danneggiati altri diritti fondamentali come, per esempio, nel caso di discorsi di odio o di incitazione alla violenza". ${ }^{132}$ Una condanna per diffamazione che comporti una pena di reclusione per aver insultato un pubblico ufficiale può configurare, di conseguenza, una violazione della Convenzione. ${ }^{133}$

\section{CONCLUSIONE}

Il presente capitolo ha dimostrato che gli organismi internazionali e regionali per i diritti umani e le corti hanno sviluppato, nel corso degli anni, un crescente corpus di norme e principi per la protezione e la sicurezza dei giornalisti e degli operatori mediatici. Infatti, la molteplicità di fonti - giurisprudenza delle corti regionali, risoluzioni degli organismi ONU per i diritti umani, dichiarazioni e rapporti di autorità internazionali ed esperti, e il Piano di azione dell'ONU - offrono nel loro complesso un corpus normativo così come una guida di policy attendibile per gli Stati nello dare risposte effettive alla violenza contro i giornalisti e gli operatori mediatici nel mondo al giorno d'oggi e per la relativa impunità che spesso sussiste. Una maggiore consapevolezza e la comprensione del contesto giuridico e di policy da parte degli Stati, delle ONG e dei media stessi faciliterebbe sicuramente l'attuazione degli obblighi internazionali degli Stati e le responsabilità per contrastare la sfida dei continui attacchi contro i giornalisti e gli operatori mediatici, così come le violazioni che ne emergono.

130 Corte europea dei diritti dell'uomo, Radio France ed altri c. Francia, Ricorso n. 53984/00, Sentenza del 30 marzo 2004, paragrafo 40; Corte Europea dei diritti dell'uomo, Lindon, Otchakovsky-Laurens e July c. Francia, Ricorso n. 21279/02 and 36448/02, 22 ottobre 2007, paragrafo 59.

131 Corte europea dei diritti dell'uomo, Mahmudov and Agazade c. Azerbaigian, Ricorso n. 35877/04, Sentenza del 18 dicembre 2008, paragrafo 51.

132 Corte europea dei diritti dell'uomo, Fatullayev c. Azerbaigian, Ricorso n. 40984/05, Sentenza del 22 aprile 2010, paragrafo 103.

133 Corte europea dei diritti dell'uomo, Cumpănă and Mazăre c. Romania, Ricorso n. 33348/96, 17 dicembre 2004, paragrafo 116. 


\section{BIBLIOGRAFIA}

Akkoc R. (2014), "Gaza conflict: foreign journalist among five killed after an Israeli missile explodes”, The Daily Telegraph, 13 agosto 2014.

Alto commissariato delle Nazioni Unite per i diritti umani (2012), Dichiarazione congiunta relativa ai crimini contro la libertà di espressione, giugno 2012, disponibile su www.ohchr.org/en/NewsEvents/Pages/DisplayNews.aspx?NewsID=123 84\&LangID=E, consultato il 14 luglio 2015.

Alto commissariato delle Nazioni Unite per i diritti umani (2014), "International freedom of expression rapporteurs urge stronger protection of journalists covering conflicts”, comunicato stampa, 1 settembre 2014.

Article 19 (2013), "How to protect yourself during protests: A19 video tutorial”, 13 dicembre 2013, disponibile su www.article19.org/resources.php/resource/37406/ en/how-to-protect-yourself-during-protests:--a19-video-tutorial, consultato il 13 luglio 2015 .

Assemblea generale delle Nazioni Unite (2011), Rapporto del Relatore speciale all'Assemblea generale relative al diritto alla libertà di opinione e di espressione esercitate su internet, 10 agosto 2011, A/66/290.

Assemblea generale delle Nazioni Unite (2013), Risoluzione dell'Assemblea generale 68/163 del 18 dicembre 2013, A/RES/68/163.

Assemblea parlamentare del Consiglio d'Europa (2005), Risoluzione 1438 (2005) relativa alla libertà di stampa e le condizioni di lavoro dei giornalisti nelle zone di conflitto, adottata il 28 aprile 2005.

Assemblea parlamentare del Consiglio d'Europa (2007a), Risoluzione 1535 (2007) relativa alle minacce alle vite e alla libertà di espressione dei giornalisti, adottata il 25 gennaio 2007.

Assemblea parlamentare del Consiglio d'Europa (2007b), Risoluzione 1577 (2007) denominata "Verso la depenalizzazione della diffamazione", adottata il 4 ottobre 2007.

Assemblea parlamentare del Consiglio d'Europa (2010), Raccomandazione 1897 (2010) denominata "Rispetto della libertà dei media", adottata il 27 gennaio 2010.

Assemblea parlamentare del Consiglio d'Europa (2011), Raccomandazione 1950 (2011) denominata "Protezione delle fonti giornalistiche", adottata il 25 gennaio 2011.

Assemblea parlamentare del Consiglio d'Europa (2013), Risoluzione 1920 (2013) denominata "Lo stato di libertà dei mezzi d'informazione in Europa", adottata il 24 gennaio 2013.

Barton A. e Storm H. (2014), Violence and harassment against women in the news media: a global picture, International Women's Media Foundation and International News Safety Institute, 10 marzo 2014.

Browne E. et al. (2012), Safety of journalists research pack, Centre of Governance and Human Rights (CGHR), Università di Cambridge, Cambridge, giugno 2012. 
Callimachi R. (2014), "Militant group says it killed American journalist in Syria”, The New York Times, 19 agosto 2014.

Comitato dei Ministri del Consiglio d'Europa (2000), Raccomandazione n. R (2000) 7 relativa al diritto dei giornalisti di non rivelare le proprie fonti di informazioni, adottata l'8 marzo 2000.

Comitato dei Ministri del Consiglio d'Europa (2011), Raccomandazione CM/ $\operatorname{Rec}(2011) 7$ del Comitato dei Ministri agli Stati Membri relativa ad una nuova nozione di media, adottata il 21 settembre 2011.

Comitato dei Ministri del Consiglio d'Europa (2012), "Dibattito tematico sulla 'sicurezza dei giornalisti’: documento di riflessione presentato dal Segretario Generale", 22 marzo 2012, Documento d'informazione del Consiglio d'Europa, SG/ $\operatorname{Inf}(2012) 6$.

Comitato dei Ministri del Consiglio d'Europa (2013a), "Dibattito tematico sulla 'sicurezza dei giornalisti - misure da adottare al fine di migliorare l'attuazione delle norme in materia di diritti umani'. Documento di riflessione presentato dal Segretario Generale”, 2 dicembre 2013, Documento d'informazione del Consiglio d'Europa SG/Inf(2013)42.

Comitato dei Ministri del Consiglio d'Europa (2013b), Dichiarazione del Comitato dei Ministri sulla protezione dei giornalisti e la sicurezza dei giornalisti e di altri soggetti, adottata dal Comitato dei Ministri il 30 aprile 2014 nel corso della 1198a riunione dei Delegati dei Ministri.

Comitato dei Ministri del Consiglio d'Europa (2014a), "Dibattito tematico sulla 'sicurezza dei giornalisti - misure da adottare al fine di migliorare l'attuazione delle norme in materia di diritti umani', proposte di follow up': documento di riflessione presentato dal Segretario Generale”, 20 gennaio 2014, Documento d'informazione del Consiglio d'Europa SG/Inf(2014)2.

Comitato dei Ministri del Consiglio d'Europa (2014b), Dichiarazione relativa alla protezione del giornalismo e la sicurezza dei giornalisti e di altri attori mediatici, 30 aprile 2014.

Comitato internazionale della Croce Rossa (2012), "When journalists' safety is at stake, the ICRC hotline can help", intervista, 2 maggio 2012, disponibile su www.icrc.org/eng/resources/documents/interview/2012/protection-journalists-in terview-2012-05-02. htm, consultato il 13 luglio 2015.

Comitato per i diritti umani delle Nazioni Unite (1982), Commento generale n. 6 sull'articolo 6 sul diritto alla vita, UN Doc HRI/GEN/1/Rev.6.

Comitato per i diritti umani delle Nazioni Unite (2003), Commento generale n. 6 sull'articolo 6 sul diritto alla vita, UN Doc HRI/GEN/1/Rev.6.

Comitato per i diritti umani delle Nazioni Unite (2004), Commento generale n. 31 sulla natura dell'obbligo giuridico generale imposto agli Stati parte della Convenzione dall'articolo 2, 29 marzo 2004, CCPR/C/21/Rev.1/Add.13.

Comitato per i diritti umani delle Nazioni Unite (2011), Commento generale n. 34 sull'articolo 19 sulla libertà di opinione e di espressione, CCPR/C/GC/34, 11 settembre 2011. 
Comitato per la protezione dei giornalisti (2012), Journalist security guide, disponibile su https://cpj.org/reports/2012/04/journalist-security-guide.php, consultato il 15 luglio 2015.

Comitato per la protezione dei giornalisti (2014a), The road to justice: breaking the cycle of impunity, ottobre 2014.

Comitato per la protezione dei giornalisti (2014b), "International journalists killed at high rate in 2014; Middle East deadliest region”, 23 dicembre 2014, disponibile su https://cpj.org/reports/2014/12/international-journalists-killed-at-high-rate-i n-2014-middleeast-deadliest-region-for-press.php, consultato il 13 luglio 2015.

Commissario per i diritti umani del Consiglio d'Europa (2011), "La protezione dei giornalisti dalla violenza", Documento tematico, 4 ottobre 2011, Comm$\mathrm{DH}(2011) 44$.

Commissario per i diritti umani del Consiglio d'Europa (2012), "Safety of online media actors as a precondition for media pluralism and freedom of expression", Discorso di Nils Muižnieks presso il Joint Open Forum, organizzatori Unione europea di radiodiffusione, Consiglio d'europa, OSCE e UNESCO, Internet Governance Forum, Baku, 7 novembre 2012, CommDH/Speech(2012)14.

Commissario per i diritti umani del Consiglio d'Europa (2014), “Keep the press free", comunicato stampa in occasione della libertà di stampa, 2 maggio 2014.

Commissione africana sui diritti dell'uomo e dei popoli (2002), "Dichirazione dei principi sulla lubertà di espressione in Africa”, Banjul, 23 ottobre 2002

Commissione interamericana dei diritti umani dell'Organizzazione degli Stati americani (OSA) (2000), Dichiarazione di principi sulla libertà di espressione, approvata dalla Commissione interamericana dei diritti umani durante la sua $108^{\circ}$ sessione regolare, tenutasi dal 2-20 ottobre 2000.

Commissione interamericana dei diritti umani dell'Organizzazione degli Stati americani (OSA) (2008a), "Special study on the status of investigations into the murder of journalists during the 1995-2005 period for reasons that may be related to their work in journalism", Ufficio del Relatore speciale per la libertà di espressione, OEA/Ser.L/V/II.131 Doc 35, 8 marzo 2008.

Commissione interamericana dei diritti umani dell'Organizzazione degli Stati americani (OSA) (2008b), Rapporto annuale 2008, Rapporto annual dell'Ufficio del Relatore special per la libertà di espressione, capitolo IV ("A hemispheric agenda for the defense of freedom of expression”), OEA/Ser.L/V/II.134 Doc. 5 rev. 1., 25 febbraio 2009.

Commissione interamericana dei diritti umani dell'Organizzazione degli Stati americani (OSA) (2011), "Access to justice for women victims of sexual violence in Mesoamerica”, OEA/Ser.L/V/II Doc 63, 9 dicembre 2011.

Commissione interamericana dei diritti umani dell'Organizzazione degli Stati americani (OSA) (2013), Violence against journalists and media workers: InterAmerican standards and national practices on prevention, protection and prosecution of perpetrators, Organization of American States, Office of the Special Rapporteur for Freedom of Expression, Catalina Botero Marino, 31 dicembre 2013, OEA/Ser.L/V/II, CIDH/RELE/INF.12/13. 
Commissione interamericana dei diritti umani dell'Organizzazione degli Stati americani (OSA) (2014a), "Office presents report on violence against journalists and media workers”, Organization of American States, Ufficio del Relatore speciale per la libertà di stampa, comunicato stampa 75/14, 21 luglio 2014.

Commissione interamericana dei diritti umani dell'Organizzazione degli Stati americani (OSA) (2014b), "Impunity for violations of the right to freedom of expression in the Americas”, Multimedia Section, 27 marzo 2015, disponibile su http:/ /oas.org/es/cidh/multimedia/sesiones/150/default.asp, consultato il 14 luglio 2015.

Commissione per i diritti umani delle Nazioni Unite (2005), Rapporto del gruppo di lavoro sulla detenzione arbitraria, 12 dicembre 2005, E/CN.4/2006/7.

Conferenza dei Ministri del Consiglio d'Europa responsabili per i media e la società dell'informazione (2013), Risoluzione 3 sulla sicurezza dei giornalisti, Belgrado, 3 novembre 2013 .

Consiglio dell'Unione Europea (2014), Linee guida dell'Unione europea sui diritti umani relative alla libertà di espressione, Riunione del Consiglio affari esteri, Bruxelles, 12 maggio 2014.

Consiglio di sicurezza delle Nazioni Unite (2006), Risoluzione del Consiglio di sicurezza 1738 (2006) del 23 dicembre 2006, S/RES/1738.

Consiglio di sicurezza delle Nazioni Unite (2012), Rapporto del Segretario Generale sulla protezione dei civili nei conflitti armati, 22 maggio 2012, S/2012/376.

Consiglio Economico e Sociale delle Nazioni Unite (1989), Principi relativi alla prevenzione efficace di esecuzioni extragiudiziarie, illegali e sommarie, Risoluzione del Consiglio Economico e Sociale 1989/65 del 24 maggio 1989, E/ 1989/89.

Consiglio per i diritti umani delle Nazioni Unite (2010), "Tenth anniversary joint declaration: ten key challenges to freedom of expression in the next decade", Rapporto del Relatore speciale sulla promozione e la protezione della libertà di opinione e di espressione, Appendice, 25 marzo 2010, A/HRC/14/23/Add.2.

Consiglio per i diritti umani delle Nazioni Unite (2011), "Key trends and challenges to the right of all individuals to seek, receive and impart information and ideas of all kinds through the Internet", Rapporto del Relatore special al Consiglio per i diritti umani, 16 maggio 2011, A/HRC/17/27.

Consiglio per i diritti umani delle Nazioni Unite (2012a), Risoluzione del Consiglio per i diritti umani 21/12 del 27 settembre 2012, A/HRC/RES/21/12.

Consiglio per i diritti umani delle Nazioni Unite (2012b), Rapporto del Relatore speciale sulla promozione e la protezione della libertà di opinione e di espressione, Frank la Rue, 4 giugno 2012, A/HRC/20/17.

Consiglio per i diritti umani delle Nazioni Unite (2012c), Rapporto del Relatore speciale sulle esecuzioni extragiudiziali, sommarie e arbitrarie, Christof Heyns, 10 aprile 2012, A/HRC/20/22.

Consiglio per i diritti umani delle Nazioni Unite (2013a), Decisione del Consiglio per i diritti umani 24/116 del 26 settembre 2013, A/HRC/DEC/24/116. 
Consiglio per i diritti umani delle Nazioni Unite (2013b), Risoluzione del Consiglio per i diritti umani 23/2 relativa al ruolo della libertà di opinione e di espressione nell'emancipazione femminile, 13 giugno 2013, A/HRC/RES/23/2.

Consiglio per i diritti umani delle Nazioni Unite (2014a), Risoluzione del Consiglio per i diritti umani 27/5 del 25 settembre 2014, A/HRC/RES/27/5.

Consiglio per i diritti umani delle Nazioni Unite (2014b), Sintesi del tavolo di discussion del Consiglio per i diritti umani sulla questione della sicurezza dei giornalisti, preparata dall'Ufficio dell'Alto commissario per i diritti umani, 2 luglio 2014, A/HRC/27/35 versione provvisoria inedita.

Consiglio per i diritti umani delle Nazioni Unite (2014c), Rapporto del gruppo di lavoro sulla detenzione arbitraria, 30 luglio 2014.

Corte interamericana dei diritti umani (1985), "Compulsory membership in an association prescribed by law for the practice of journalism (Articles 13 and 29 American Convention on Human Rights)", Parere consultivo OC-5/85 del 13 novembre 1985, Serie A n. 5.

Corte interamericana dei diritti umani (2003), "Juridical condition and rights of undocumented migrants", Parere consultivo OC-18/03 del 17 settembre 2003, Serie A n. 18.

Dart Centre for Journalism and Trauma (2015) "Global safety principles and practices”, 12 febbraio 2015, disponibile su http://dartcenter.org/content/global-safety principles-and-practices\#.VQsHRym0BLP, consultato il 13 luglio 2015.

Draghici C. e Woods L. (2011), "Safety of journalists: a responsibility for the world", ricerche e raccomandazioni della conferenza di lavoro sul tema "the Initiative on Impunity and the Rule of Law", uno studio strategico ed un progetto per il Centre for Law, Justice and Journalism (CLJJ), City University London, e del Centre for Freedom of the Media (CFOM), University of Sheffield, svoltosi presso la City University, Londra, il 1 giugno 2011.

Düsterhöft I. (2013), “The protection of journalists in armed conflicts: how can they be better safeguarded?" Utrecht Journal of International and European Law, 29, 76, pp. 4-22.

European Court of Human Rights Research Division (2011), "Positive obligations on member states under Article 10 to protect journalists and prevent impunity", document di ricerca, dicembre 2011.

Fisher M. (2014), "If police in Ferguson treat journalists like this, imagine how they treat the residents", Vox, 26 agosto 2014.

Henrichsen J. R., Betz M. e Lisosky J. M. (2015), Building digital safety for journalism: a survey of selected issues, UNESCO, Parigi.

Heyns C. e Srinivasan S. (2013), "Protecting the right to life of journalists: the need for a higher level of engagement”, Human Rights Quarterly, 35, 2, pp. 304-332.

IMEMC News \& Agencies (2014) “17 journalists killed in Gaza since beginning of Israeli aggression”, International Middle East Media Center, 26 agosto 2014. 
Leach P. (2013), "The principles which can be drawn from the case-law of the European Court of Human Rights relating to the protection and safety of journalists and journalism", MCM(2013)012 [CDMSI(2013)Misc3], disponibile su www.coe.int/t/dghl/standardsetting/media/Belgrade2013/MCM(2013)012_en_L each_ProtectionofJournalists.pdf, consultato il 22 luglio 2015.

McGonagle T. (2013), "How to address current threats to journalists: The role of the Council of Europe in protecting journalists and other media actors", rapport preparato per la Conferenza dei Ministri del Consiglio d'Europa responsabili per i media e la società dell'informazione sulla "Libertà di espressione e democrazia nell'era digitale: opportunità, diritti e responsabilità”, Belgrado 7-8 novembre 2013, MCM (2013) 009.

Mijatović D. (2011), "Protection of journalists from violence", in Commissario del Consiglio d'Europa per i diritti umani, Human rights and a changing media landscape, Consiglio d'Europa, Strasburgo, pp 21-45.

O'Flaherty M. (2012), "Freedom of expression: Article 19 of the International Covenant on Civil and Political Rights and the Human Rights Committee's General Comment No. 34", Human Rights Law Review, 12, 4, pp. 627-54.

Organizzazione delle Nazioni Unite e Organizzazione degli Stati americani (2013), Joint Declaration on violence against journalists and media workers in the context of protests, by the UN Special Rapporteur on the Protection and Promotion of the Right to Freedom of Opinion and Expression and the Special Rapporteur for Freedom of Expression of the OAS Inter-American Commission on Human Rights, 13 settembre 2013, disponibile su www.oas.org/en/iachr/expression/sho warticle.asp?artID=931\&lID=1, consultato il 14 luglio 2015.

OSCE (2011), "Vilnius recommendations on safety of journalists", Rappresentante per la libertà dei mezzi d'informazione dell'Organizzazione per la Sicurezza e la Cooperazione in Europa, 8 giugno 2011, CIO.GAL/111/11.

OSCE (2013), "End Impunity Campaign Launched", Rappresentante per la libertà dei mezzi d'informazione dell'Organizzazione per la Sicurezza e la Cooperazione in Europa, 16 dicembre 2013, updated 14 agosto 2014.

OSCE (2014a), Safety of journalists guidebook, II ed., Rappresentante per la libertà dei mezzi d'informazione dell'Organizzazione per la Sicurezza e la Cooperazione in Europa, Vienna.

OSCE (2014b), “Journalists' safety remains biggest media freedom challenge in Ukraine, says OSCE representative”, comunicato stampa, Rappresentante per la libertà dei mezzi d'informazione dell'Organizzazione per la Sicurezza e la Cooperazione in Europa, 20 agosto 2014.

OSCE (2014c), "Russian authorities must end impunity for attacks on journalists, says OSCE Representative following another attack in Pskov", comunicato stampa, Rappresentante per la libertà dei mezzi d'informazione dell'Organizzazione per la Sicurezza e la Cooperazione in Europa, 30 agosto 2014.

OSCE (2014d), "OSCE representative calls on US law enforcement authorities to investigate arrests of reporters covering Ferguson demonstrations”, comunicato stampa, Rappresentante per la libertà dei mezzi d'informazione dell'Organizzazione per la Sicurezza e la Cooperazione in Europa, 19 agosto 2014. 
OSCE (2014e), "OSCE media freedom representative concerned about ban on journalist from entering Crimea”, comunicato stampa, Rappresentante per la libertà dei mezzi d'informazione dell'Organizzazione per la Sicurezza e la Cooperazione in Europa, 18 agosto 2014.

OSCE (2014f), "OSCE Representative says media has right to cover civil disturbances without intimidation”, comunicato stampa, Rappresentante per la libertà dei mezzi d'informazione dell'Organizzazione per la Sicurezza e la Cooperazione in Europa, 14 agosto 2014.

OSCE (2015), “The growing safety threat to female journalists online”, Rappresentante per la libertà dei mezzi d'informazione dell'Organizzazione per la Sicurezza e la Cooperazione in Europa, Dunja Mijatović, Communiqué 02/2015, 6 febbraio 2015.

Parmar S. (2014), "The protection and safety of journalists: a review of international and regional human rights law", document di lavoro preparato per il Seminario e Dialogo interregionale sulla protezione dei giornalisti avente per argomento "Towards an effective framework of protection for the work of journalists and an end to impunity", Corte europea dei diritti dell'uomo, Strasburgo, lunedì 3 novembre 2014, disponibile su www.inter-justice.org, consultato il 13 luglio 2015.

Parmar S. (2015), "The Paris attacks and global norms on freedom of expression", Tom Lantos Institute Public Lecture series "From the courtroom to the street: creating a popular culture of human rights”, Eötvös Loránd University, Budapest, 17 febbraio 2015.

Radio Free Europe/Radio Liberty Azerbaijani Service (2014), “Azerbaijani journalist severely beaten”, 30 agosto, 2014.

Reporter senza frontiere (2002), "Charter for the safety of journalists working in war zones or dangerous areas”, 30 maggio 2002.

Reporter senza frontiere (2006), Handbook for journalists, 17 febbraio 2006.

Saul B. (2008), "The international protection of journalists in armed conflict and other violent situations", Australian Journal of Human Rights 14, 1, pp. 99-140.

Somaiya R. and Haughney C. (2014), "From Missouri to Syria: journalists are becoming targets", The New York Times, 20 agosto 2014.

UNESCO (1997), Risoluzione 29 della Conferenza Generale dell'UNESCO “Condanna della violenza contro i giornalisti”, Conferenza Generale, 29a sessione, novembre 1997.

UNESCO (2012), Piano di azione delle Nazioni Unite sulla sicurezza dei giornalisti e la questione dell'impunità, Programma Internazionale per lo Sviluppo della Comunicazione (IPDC), aprile 2012, CI-12/CONF.202/6.

UNESCO (2013a), Indicatori della sicurezza dei giornalisti: livello internazionale, 25 luglio 2013, UNESCO, Parigi.

UNESCO (2013b), Indicatori della sicurezza dei giornalisti: livello nazionale, 25 luglio 2013, UNESCO, Parigi.

UNESCO (2013c), Applying UNESCO's journalists' safety indicators (JSIs): a practical guidebook to assist researchers, 25 luglio 2013, UNESCO, Parigi. 
UNESCO (2014), World trends in freedom of expression and media development, Parigi.

UN News Centre (2013a), "Veteran journalists, UN deputy chief urge Security Council to do more to protect reporters", 17 luglio 2013.

UN News Centre (2013b), "Security Council must pay more attention to attacks on journalists, UN expert warns”, 13 dicembre 2013. 
